\title{
MAGNET SUPPORT AND ALIGNMENT*
}

\author{
ROBERT E. RULAND ${ }^{\diamond}$ \\ Stanford Linear Accelerator Center, Stanford University, Stanford, CA 94309
}

\subsection{Introduction}

From theoretical design of the storage ring and injection system, we move to physical installation. The challenge facing the alignment team is to translate a theoretical storage ring layout designed in Cartesian space into a physical ring in geocentric space- to transform a list of theoretical coordinates into a physical system in which each component lies at its design location to within a specified tight tolerance. How to accomplish this transformation is the subject of this chapter.

As alignment tolerances get ever tighter, the interplay of alignment with mechanical engineering becomes ever more important. In fact, accelerator alignment has advanced so far that mechanical uncertainties now exceed observational uncertainties. Of the mechanical issues bearing upon alignment, one of the most crucial is the magnet supports; these must provide both stability and a fineness of motion substantially exceeding the final alignment tolerances. This chapter therefore includes a section on mechanical support systems and their implications for alignment.

This chapter covers three topics: mechanical schemes to support and align storage ring and injection system components; survey and alignment of those components; and ground motion.

The first section addresses magnet supports (girders and individual magnet stands) and mechanical adjustment systems (shims, struts, and cross slides).

The second section focuses on the alignment of synchrotrons, storage rings and injection lines, and examines the propagation of errors associated with these processes. The relationship of the lattice coordinate system to the selected layout coordinate system, and the subsequent computation of ideal component coordinates are described, followed by a broad overview of the sequence of alignment activities from the initial absolute positioning to the final smoothing. Emphasis is given to the relative alignment of components; in particular, to the importance of incorporating methods to remove residual systematic effects in surveying and alignment operations.

The third section reviews ground motion issues, and describes measures for alleviating disturbances.

\subsection{Magnet Supports}

Magnet supports are the interface that allows mechanical mounting of components and their subsequent alignment to a nominal position in three-dimensional space. Supports thus provide two functions: that of a spacer to bring the component close to its ideal position, and that of a fine motion system to enable the surveyor to move the component to its ideal location within the required tolerance.

*Work supported by Department of Energy contract DE-AC03-76SF00515.

$\checkmark$ Author e-mail: ruland@slac.stanford.edu and FAX: (415) 926-4055. 
It is essential to understand that Magnets, Supports, and Survey and Alignment are interrelated. Ideally, one person would be responsible for all these functions. In larger projects, beyond the scope of one such manager, the responsible parties must be in regular communication. A magnet designed without supports in mind can be quite impossible to hold onto. ${ }^{1}$ A support system that holds the magnets up, but requires a hammer to operate, renders impossible the achievement of tight tolerances. Magnets, Supports, and Survey and Alignment must be designed as a system.

\subsubsection{Spacers}

Components, with their adjustment systems, are rarely mounted directly to the floor or to an elevated concrete structure. Instead, girders or individual stands are used to hold a component at its approximate position and elevation above the floor. These spacers serve as the backbone on which the more precisely machined adjustment systems can be mounted.

\subsubsection{Girders}

A girder is a strongback or platform onto which a group of components can be mounted at beam height. Girders simplify the installation in cases when many small components need to be supported immediately adjacent to one another, as is often the case in larger size machines $(>100 \mathrm{~m})$. The major advantages of a girder support system over individual stands are:

- The girder isolates individual components from ground settlements, since the whole group of components moves up or down together. Any settlement can be corrected by adjusting the position of one girder, rather than many support stands.

- To bring the magnet poles as close as possible to the beam in the latest generation of machines, the clearance between the pole tips and the vacuum chamber is very small, allowing little motion of the magnet with respect to the chamber. A global position adjustment of individual components requires many iterations and much time, unless all the components are mounted together and move as one monolith.

- As vacuum chambers become increasingly complex, it is often impossible to achieve and retain the correct shape in the production process. Whereas magnet supports should generally be kinematic (i.e., provide only the minimal number of constraints), for vacuum chambers, a heavily overconstrained system is often required so that the chamber can be pushed and pulled into shape. Such a system will work satisfactorily only if all constraints connect to the same reference body. This eliminates the use of individual stands.

- Girders can be filled with water to increase their thermal capacity, thereby slowing the rate of response of the girder to temperature variations.

- Girders can be preassembled in a shop before installation. All of the magnets and the vacuum chamber for a girder are installed and aligned to the final relative tolerance in a local girder coordinate system. Water-cooling manifolds and hoses are assembled on the girder at this stage, as are the connections of electrical circuits. All this work can be done in a production line environment rather than the tunnel, making it more efficient 
and of higher quality, with a more reliable inspection. ${ }^{2}$ Installation of the preassembled girder in the tunnel is also significantly faster.

There are two primary types of girders: steel box and concrete. Concrete girders (Fig. 1) feature two I-beamscast into a rectangular cement block and machined flat. The rail system formed by the I-beams supports the beam line components. This system is widely used at SLAC. Concrete girders have a significant cost advantage, but great care must be taken during the construction and cement curing process, for slow creep and hairline cracking can severely hamper the monolithic quality of the finished girder. The other girder type (Fig. 2) is the stress-relieved structural-steel box girder. During the machining of the top and bottom plates, all the mounting holes can be quickly, cheaply,

Fig. 1. Concrete girder as used in SLAC Final Focus.

Fig. 2. Steel girder as used in LBL ALS. Photo courtesy of Lawrence Berkeley Laboratory, University of California. 
and accurately drilled and tapped by NC machines, obviating the need for lengthy prealignment and for manual drilling and tapping of mounting holes.

\subsubsection{Individual Stands}

Individual stands are generally used in situations where components are more spread out; e.g., transport lines. The simplest form of stand is a length of pipe with plates welded to the top and bottom (Fig. 3). The diameter of the pipe is of course a function of stand height and component load. More sophisticated stands are used at SLAC in the FFTB. These stands are made of Anocast, a granite epoxy which gives the stands the appearance of a granite block molded to the specifications of the particular application?

In effect, the Anocast stands become a hybrid of stand and girder. In the FFTB some Anocast stands support a group of magnets while still maintaining the typical cross section of an individual magnet stand (Fig. 4). Measurements confirm that these stands have much better damping qualities of vibrations at higher frequencies than steel stands. Furthermore, their thermal mass dampens expansion due to variations in the ambient temperatures. Costs for steel and Anocast stands are comparable.

11.1.2 Manual Adjustment Systems

All beam components need to be moved and fixed at accurate locations by adjustment mechanisms. These systems should include the Fig. 3. Individual steel stand. following design features: 
Fig. 4. Anocast stand in SLAC FFTB.

- Adequate alignment precision: for precise adjustibility, the system's resolution should be ten times the required alignment tolerance.

- Orthogonal motion: there should be no cross coupling between the axes for small adjustment motions. For large motions, any existing coupling must be predictable.

- Kinematic mount: an overconstrained system induces stress into the support and/or component, resulting in a deformation of the component.

- Stability: the support should provide a stiff base when locked down where incidental contact will not cause movement of the magnet. It should also not deform the component during adjustment.

- A small footprint: as real estate is usually at a premium, components must often be placed very close together.

- Vibrational stiffness: typical ground motion frequencies should not be amplified by the support system.

There are two general types of adjustment mechanisms. The most common type separates the horizontal adjustment from the vertical degree of freedom. The second type combines horizontal and vertical adjustments into one system, usually implemented in a six strut layout that holds the component in a kinematic suspension. Other implementations are the CERN Adjuster System and its derivative, the CEBAF 3-D Cartridge, and the SLAC 3-D stage. 
Fig. 5. Push-push screw arrangement.

\subsubsection{One and Two-Dimension Systems}

To separate the horizontal from the vertical, a horizontal plane is generated by adjusting the height of three vertical standoffs. In its simplest implementation, the standoffs are either shim stacks or threaded rods. In the case of shim stacks, shim stock is added or removed until the plate is horizontal and the component at its ideal height, a lengthy, iterative process. Where threaded rods are used, the mounting plate rides on three screw nuts that are threaded on vertically mounted rods. Turning the nuts provides vertical translations along the $\mathrm{Y}$-axis and two rotational degrees of freedom, pitch (rotation around the $\mathrm{X}$-axis), and roll (rotation around the $\mathrm{Z}$-axis).

On this horizontal plate slide one or two plates on which the component is mounted. These plates move under the force of adjustment screws to adjust and fix the $\mathrm{Z}$ (in beam direction), $\mathrm{X}$ (perpendicular to $\mathrm{Z}$ ), and yaw (rotation around the $\mathrm{Y}$-axis) degrees of freedom. The adjustmentscrews are oftendesigned in a push-push arrangement (Fig. 5) with two opposing screws pushing on both sides of the component in a colinear arrangement. To achieve a translation, one side is loosened and the other tightened. Tightening both screws locks the position. Often the stand has only one sliding plate; in this case, the $\mathrm{X}$ and $\mathrm{Z}$ adjustments are not independent, since all adjustment screws must be loosened to permit sliding of the plate. Fine adjustment in the orthogonal direction is usually lost, and must be touched up again. Precise alignment with only a single sliding plate and push-push screw arrangement usually requires many iterations.

This basic design can be refined by replacing the above described horizontal and vertical adjuster with more sophisticated variations. The addition of spherical washers between the horizontal plate and the adjustment nuts makes the system move more smoothly. If the system is designed to carry higher loads, machine screw jacks (Fig. 6) are available that fit almost any application while still providing fine adjustment motion. Less expensive, but more limited in range, are wedge jack adjusters that are made of two wedges with the 
two sloped planes riding on each other. A horizontal motion pushes the upper wedge higher on the inclined plane, thereby providing a vertical motion. Wedge jack adjusters are available off the shelf in many load travel combinations. The push-push screw arrangement can be improved by a turnbuckle/railslide design. The two push screws are replaced by one turnbuckle, which provides both the push and pull force. The fixed end of the turnbuckle can slide on a rail oriented parallel to the other adjustment axis in order to allow two-dimensional adjustments. This design is still relatively simple and inexpensive, while complying with all the above listed requirements. To support the girders in the storage ring of the Argonne Photon Source, a combination of wedge jack adjusters (Fig. 7) and turnbuckle-type horizontal adjustment was used.

Fig. 6. Machine screw jack support.

\subsubsection{Three-Dimension Systems}

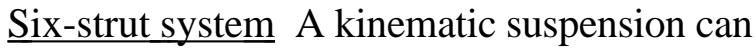
be created by arranging six adjustable length links in a 3-D truss. The three vertical struts adjust and hold the vertical translation, and the pitch and roll rotations. The three other struts (Fig. 8) are placed in the horizontal plane, two in one direction, and the third perpendicular. These three adjust and hold the $\mathrm{X}$ and $\mathrm{Z}$ translations and the yaw Fig. 7. Wedge jack adjuster as used in APS.

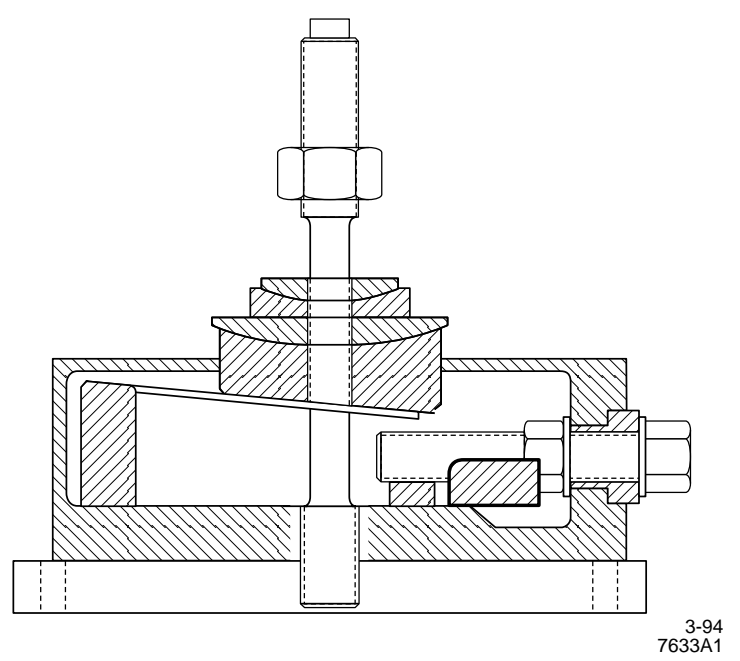


rotation. The orthogonal arrangement of the struts minimizes coupling in motion. Struts are length-adjustable rigid members with spherical joints at each end. A strut will support only an axial load, in axial compression or tension. The spherical joints at either end ensure that a strut never experiences loads in any other direction. Since all struts are in axial compression or tension, they provide very rigid support.

\subsubsection{Typical System Implemen-} tations
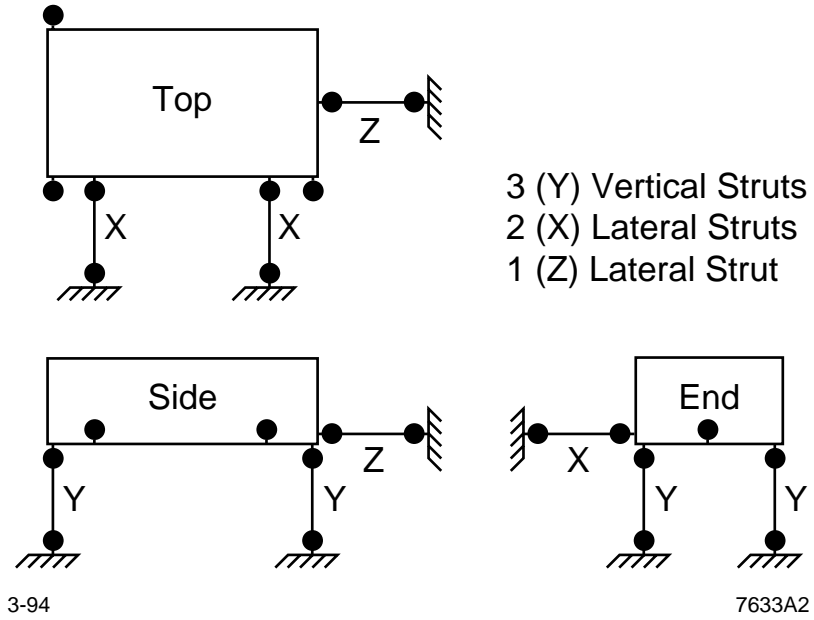

Fig. 8. Kinematic suspension.

Advanced Light Source (ALS) strut system. All components and girders at the Advanced Light Source at the Lawrence Berkeley Laboratory are supported by strut systems 4 (Fig. 9), as is the Spherical Grating Monochromator at the SSRL. The struts used for the support systems are not normal stock items. To avoid the backlash present in all regular spherical joints, the spherical rod end bearings have been squeezed in a controlled way to generate friction, which only a specific break-away torque can overcome. A shaft collar has been added at the end of each tube into which the rod end bearings thread. A portion of the tube, at each end, is turned down and slit in two directions so the shaft collar will squeeze

Figure 9. ALS strut supports. Photo courtesy of Lawrence Berkeley Laboratory, University of California. 
Fig. 10. ALS 5-ton machine screw jack strut. Photo courtesy of Lawrence Berkeley Laboratory, University of California.
Fig. 11. ALS 20-ton machine screw jack strut. Photo courtesy of Lawrence Berkeley Laboratory, University of California.

the female thread against the male thread of the rod ends to remove any backlash in the threads. The rod end bearings are all right-hand threads with one coarse thread and the other a fine thread, creating a differential threaded device which allows very high resolution adjustments. For the support of heavy loads, the tube and differential threads are replaced by an appropriately rated machine screw jack (Figs. 10, 11).

CERN cartridge. The CERN Adjuster System $^{5}$ consists of three cartridges that utilize a combination of the principles in the two styles discussed above. The improvement over the first style mechanism is that the sliding feature is replaced by the three vertically-oriented links of the kinematic suspension. The first or main cartridge works as follows (Fig. 12): the pistonended link pivots in a socket at the bottom of the base and floats within a hollow cylindrical projection from that base. At the top, the link pivots in and supports a cap whose outer skirt drapes over the cylindrical projection. The device to be positioned is

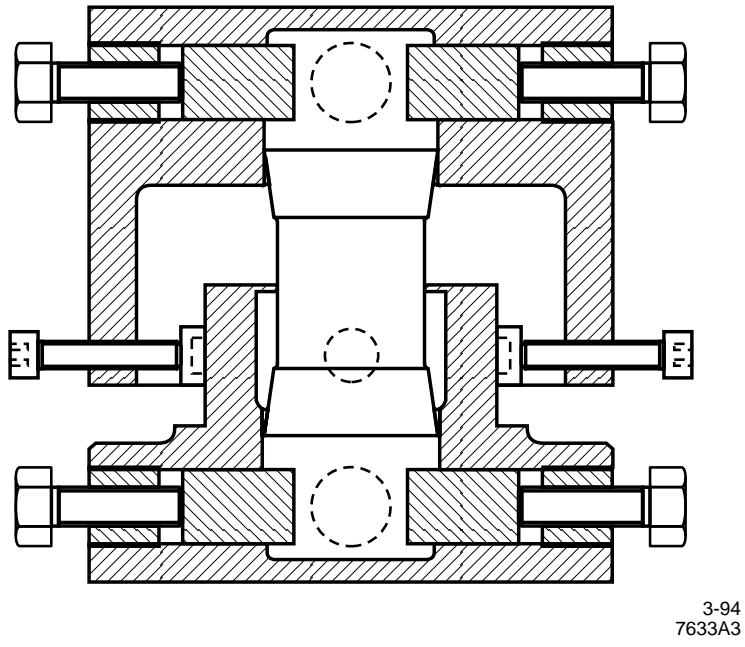

Fig. 12. CERN cartridge adjuster. 
placed on this cap. The cap is driven horizontally by four bolts threaded through the skirt of the cap, which press against four flats machined into the cylindrical projection. Lateral and longitudinal adjustment is achieved with one of these pairs of opposing push-push screws. As one bolt is loosened and the opposite bolt tightened, the cap glides easily, rocking on the vertical link. The sockets in which the link is mounted consist of cylinders in the base and cap that are filled with urethane rubber.

Four screws in the base and four screws in the cap drive in and out of this volume, compressing the rubber and driving the link or the cap higher or lower respectively, providing the verticaladjustment. The second cartridge lacks one set of opposing screws and the third cartridge lacks both sets, leaving no restraint on the cap, allowing it to float and provide only vertical adjustment. The three cartridges are placed in a triangular pattern with the set of opposing screws of the second cartridge parallel to one set of screws in the main cartridge. Use of all three cartridges provides pitch, roll, and yaw adjustment. One advantage of the CERN Adjuster System over the kinematic suspension is that there is much less coupling between the adjustments, so that alignment is more easily obtained.

CEBAF cartridge The CEBAF cartridge 6 uses many of the features of the CERN Adjuster System design. Three identical cartridges are attached to a stand through specially bored mounting holes. Each cartridge consists of a vertical cylinder and a cap (Fig. 13). The device to be adjusted is fastened to the caps of the three cartridges. The hollow, vertical cylinder has two opposing flats on its outer wall at the top, and a threaded hole in its bottom, into which is threaded a set screw. Turning this screw raises the cap, via a vertical rod through the cylinder. Lateral adjustment is by a pair of opposing screws through the skirt of the cap, registering against the flats on the cylinder. The cap glides over easily while rocking on the vertical rod. The cartridges are mounted on the stand such that the flats on two cylinders are parallel to each other and the flats on the remaining cylinder are perpendicular to the other two, providing lateral, longitudinal, and yaw adjustment. With this orientation, all degrees of freedom are constrained with no overconstraint. Locking of the movement of all screw threads is provided by locknuts.

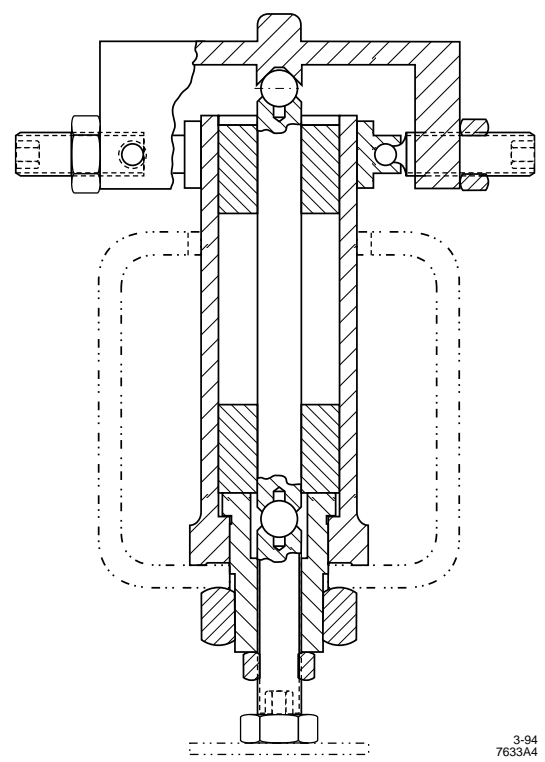

Fig. 13. CEBAF cartridge adjuster.
SLAC damping ring girder support This design contains the most basic adjustment system construction elements, a push-push screw arrangement combined with a threaded $\operatorname{rod}^{7}$ (Fig. 14). The girder is supported by three feet. Each foot's baseplate is bolted and grouted to the floor in an approximately horizontal position. Atop this baseplate sits a sliding

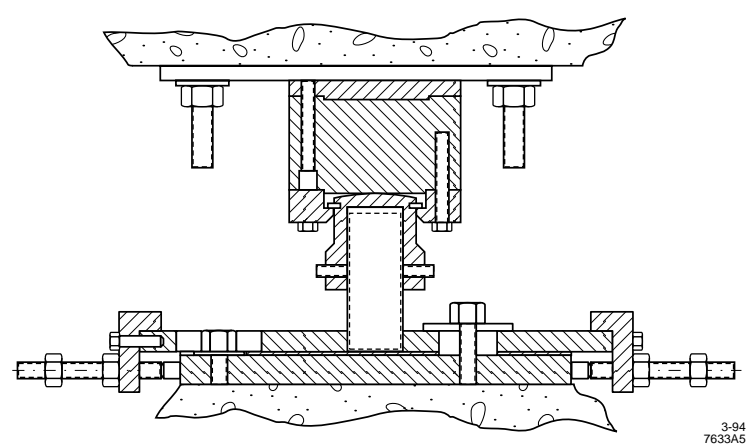

Fig. 14. SLAC Damping Ring girder support. 
plate that can be moved relative to the baseplate by the force of a two-dimensional pushpush screw arrangement. A short fine-threaded rod of substantial diameter is mounted to the sliding plate at its center. A cap-shaped nut, riding on the threads over the top of the rod, provides the vertical adjustment. The girder is mounted to this nut in a way which prevents any horizontal backlash, while still permitting it to be turned. The system is locked in the horizontal dimension by a bolt holding the sliding plate to the baseplate, and in the vertical dimension by a set screw which prevents the cap nut from turning. While this system allows relatively high resolution adjustment of heavy loads, the total system is significantly overconstrained, and must therefore be operated with great caution.

SLAC Final Focus girder support This design is similar to the Damping Ring supports, but avoids the overconstraints 8 (Fig. 15). The push-push screw arrangement is replaced by one-dimensional stages: two feet have stages oriented for lateral adjustment, while the stage at the third foot provides longitudinal motion. To decouple the cross-motion between stages, the supports are fixed to the girder in only one horizontal dimension, which is accomplished by a rail slide system. The vertical adjustment is functionally the same as on the support discussed above.

CERN LEP dipole support This system ${ }^{9}$ can provide kinematic support to a wide variety of applications, from small magnets to heavy girder modules. The general idea and functionality are taken from the CERN cartridge design, but with the vertical adjustment replaced by an adjustable-length link (Fig. 16). To minimize motion correlation, the link is made as long as possible, subject to the restraints of the specific application.

SLAC 3-D stage This is an adjustment system tailored to support a variety of components, from small quadrupoles to long narrow bends that are to be positioned to tight

Fig. 15. SLAC Final Focus girder support. 
tolerances $^{10}$ (Fig. 17). The horizontal degrees of freedom are provided by a baseplate/sliding plate arrangement. To avoid overconstraint, the adjustment motion is created by three semiturnbuckles, in which one end is a conventional rod end bearing, but the other end is a threaded stud (Fig. 18). Two of these semiturnbuckles provide the lateral adjustment, and a third gives the longitudinal adjustment. The spherical rod end bearings are threaded into blocks bolted to the base plate. The spherical bearing end is threaded onto a rail that is
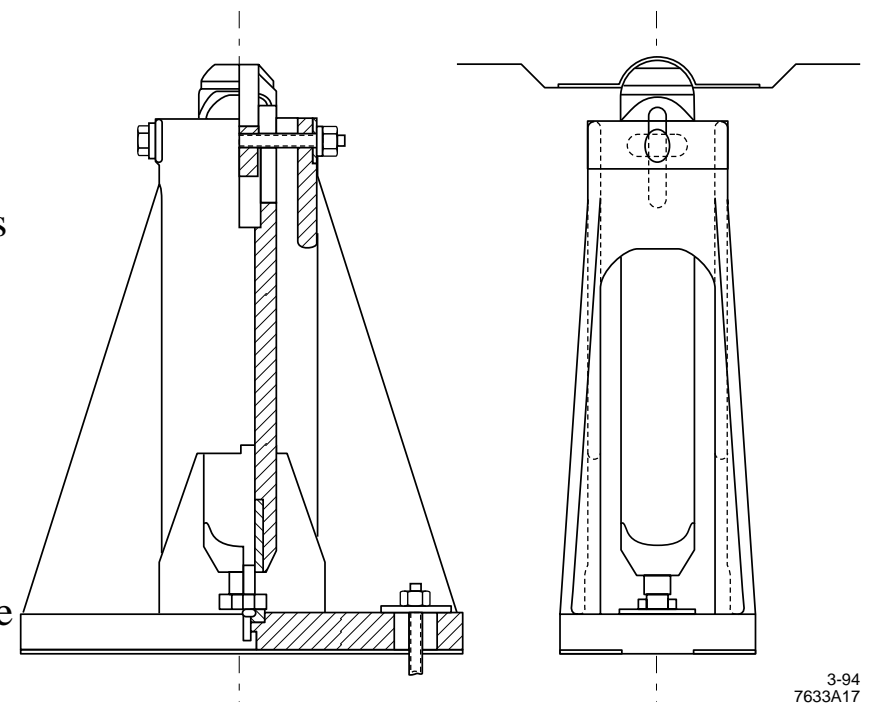
mounted on the baseplate perpen-

Fig. 16. CERN LEP Dipole support. dicular to the rod's adjustment direction. This arrangement allows the sliding plate to be adjusted in one dimension, while maintaining the adjustment in the other horizontal dimension. The vertical adjustment is created in a similarway. Three spherical rod end bearings are bolted vertically into blocks mounted to the sliding plate. Bolts through the spherical rod end bearings support the component.

Fig. 17. SLAC 3-D stage. 
DESY PETRA single component support system This system ${ }^{11}$ has been used to support quadrupoles on single stands and long dipoles on two single stands at either magnet end in the PETRA ring. The underlying scheme is now widely used in other machines at DESY. Shown below in Fig. 19 is a quadrupole sitting with three pads on three vertical screws that provide height, roll, and pitch adjustments. In the horizontal plane, two struts allow motion perpendicular to the beam. No adjustment capability along the beam axis is provided. To create a kinematic mount between the pads and screws, one screw head is resting in a groove, while the other two pads are flat.

\subsubsection{Motorized Adjustment Systems}

SLAC FFTB magnet positioners The FFTB magnet positioners ${ }^{12}$ differ from conventional positioning stages used in instruments and machine tools. The mechanism is de-

Fig. 18. Lateral adjustment layout.

signed to support loads exceeding 1 ton, while still providing smooth motion, free of hysteresis, at the micron level. The design is simple and sufficiently reliable for large scale use in the remote positioning of hundreds of magnets. Conventional crossed-slide leadscrew positioning stages are not appropriate for this application. High-resolution piezoelectric positioners ${ }^{13}$ cannot meet the load and range requirements. The remote magnet positioning mounts used in the FFTB kinematically support the magnets on roller cams. The magnet rests under gravity in a cradle formed by the cams (Fig. 20). This type of kinematic support is similar to the Kelvin Clamp $^{14}$ used in laboratory optics
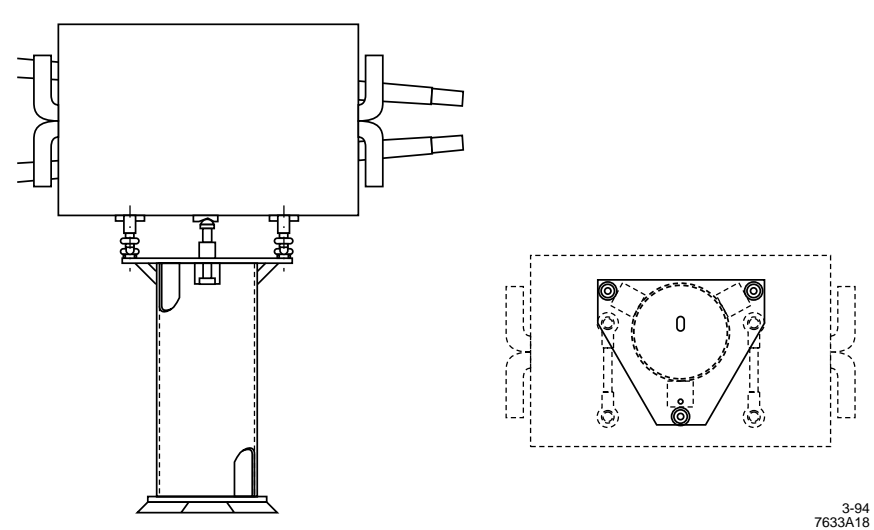

Fig. 19. DESY PETRA support system. 
and instrumentation. The V-blocks and flat plates fixed to the magnet make point or line contact with the outer bearing races of the roller cams. Rotation of the eccentric camshafts shifts the magnet position. This type of kinematic support, where the number of contact points balances the number of degrees of spatial freedom, has the advantage of avoiding all free play between the magnet and mount. The magnet always rests in contact with all of the supporting cams, regardless of their position. No precise

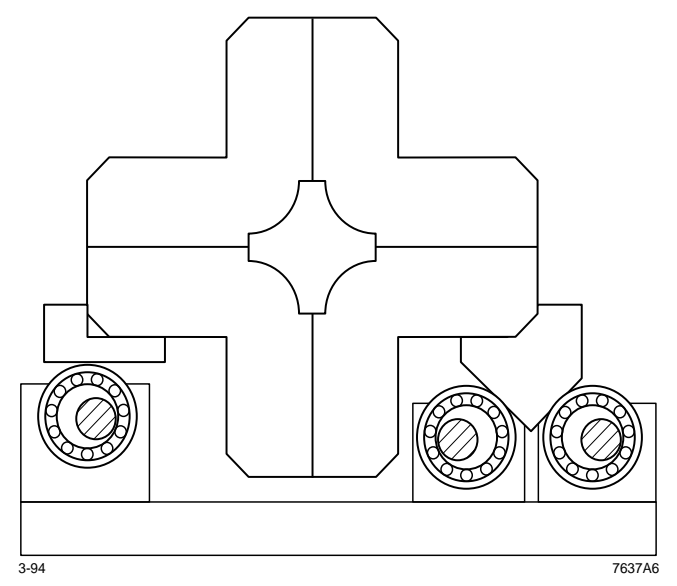

Fig. 20. Magnet positioning mount with roller cams. mechanical dimensions are needed to insure zero play. No clamping forces, other than gravity, can distort the magnet's shape. The magnet can be removed from the mount and replaced without realignment. During operation, only the inner eccentric shaft of a support cam rotates under motor control. The outer cam bearing race remains in contact with the magnet as shaft rotation lifts the magnet. In such a system, failure of the control system will only cause the cam to cycle around again. Magnet motions are strictly bounded by the design geometry. Limit switches are not needed for over-travel protection. All support cams are arranged so that gravity applies a load torque to each cam shaft drive train. This torque removes all backlash, except at the extremes of cam lift. All parts move by pure rolling motion, and are free of the hysteresis typical of intermittent and reversing sliding motion. This mount can adjust the horizontal

Fig. 21. FFTB magnet remote positioner. 
and vertical position of the magnet, as well as the magnet's roll angle around the beam axis. The magnet's longitudinal position along the beam line, as well as its alignment to the beam direction in this implementation are fixed in the support mount, and not remotely adjustable. Figure 21 shows the three-motor positioning mount used to support FFTB quadrupole magnets. Kinematic roller cam supports can be applied to a variety of geometries. The barrel containing the final triplet of quadrupole lenses for the Stanford Linear Collider is supported on five roller cam supports. This 5-m-long 6-ton assembly is remotely adjustable in pitch and yaw, as well as roll, vertical, and horizontal position.

ESRF servo-controlled jacks Predicted ground motion of more than $1 \mathrm{~mm}$ per year led to the development of a remote vertical alignment system. A computer-controlled hydrostatic leveling system was installed in the storage ring with three measurement stations on each girder. These girders are kinematically supported by three vertical motorized screw jacks, which are interfaced to the control system. The horizontal adjustment is provided by a geardriven $\mathrm{X}-\mathrm{Z}$ stage mounted on top of the vertical jacks. ${ }^{15}$ First results indicate that it takes about two minutes to map the entire ring, and then only two hours to vertically align all girders. ${ }^{16}$

\subsection{Alignment}

A Survey and Alignment team's charter in building light sources is the physical positioning of all machine components, including magnets, insertion devices, detectors, and diagnostic devices, according to layout specifications. The task of positioning magnets can be broken down into six major subtasks:

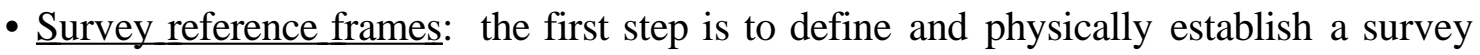
coordinate system appropriate to the project site and size. Control monuments are established to represent this reference grid.

- Layout description reference frame: the beam line is designed and specified in a lattice coordinate system. Coordinate transformations, including rotations and transformations, need to be defined to relate this to the survey reference frame.

- Fiducialization: the fiducialization of a component relates its effective magnetic or electrical centerline to external reference points that are accessible to subsequent survey measurements.

- Prealignment of girders: after components and vacuum chambers are mounted on a girder, they are aligned relative to a girder coordinate system.

- Absolute positioning: girders are positioned with respect to the global reference grid.

- Relative positioning: local tolerances are achieved by the relative alignment of adjacent components.

\subsubsection{Survey Reference Frames}

The goal is to define a computational reference frame - a mathematical model of the space in which the surveyor takes his measurements and performs his data analysis. Transformation algorithms and parameters between the surveying space and the machine layout coordinate system must be defined. 


\subsubsection{Surveying Space}

Ancient civilizations realized that the earth is round, and geodesy was born when the Greek Eratosthenes (born 276BC) first attempted to determine its size. ${ }^{17}$ The earth is actually of a more complex shape, the modeling of which is not easy. Three surfaces are of importance to the geodesist studying the shape of the earth:

i) The terrain surface is irregular, departing by up to $8000 \mathrm{~m}$ above and $10000 \mathrm{~m}$ below the mean sea level.

ii) The geoid is the reference surface described by gravity; it is the equipotential surface at mean sea level that is everywhere normal to the gravity vector. Although it is a more regular figure than the earth's surface, it is still irregular due to local mass anomalies that cause departures of up to $150 \mathrm{~m}$ from the reference ellipsoid. As a result, the geoid is nonsymmetric and its mathematical description nonparametric, rendering it unsuitable as a reference surface for calculations. It is, however, the surface on which all survey measurements are made as almost all survey instruments are set up with respect to gravity. Even the satellites now used for GPS surveys follow obits determined by gravity.

iii) The spheroid or ellipsoid is the regular figure that most closely approximates the shape of the earth, and is therefore widely used in astronomy and geodesy to model the earth (Fig. 22). Being a regular mathematical figure, it is the sufface on which calculations can be made. Nevertheless, in performing these calculations, account must be taken of the discrepancy between the ellipsoid and the geoid. The deflection (or deviation) of the vertical is the angle of divergence between the gravity vector (normal to the geoid) and the ellipsoid normal (Fig. 23). Several different ellipsoids have been defined and chosen that minimize geoidal discrepancies on a global scale, but for a survey engineering project, it is sufficient to define a best-fit local spheroid that

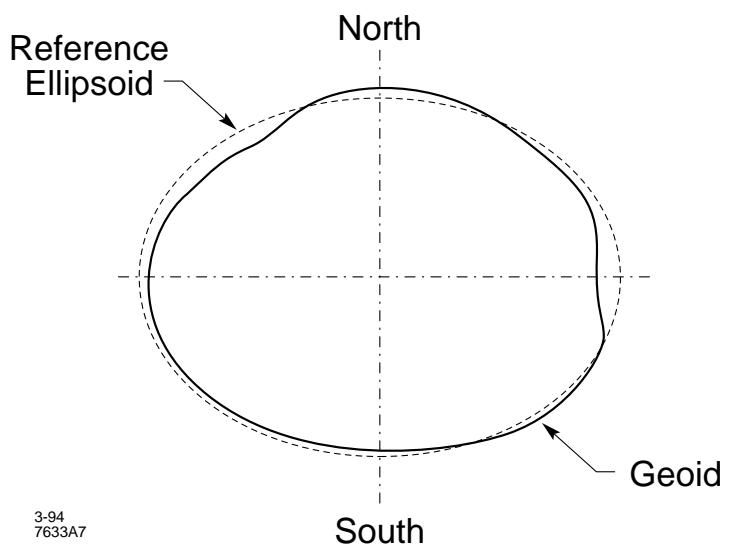

Fig. 22. Spheroid (ellipsoid) and geoid.

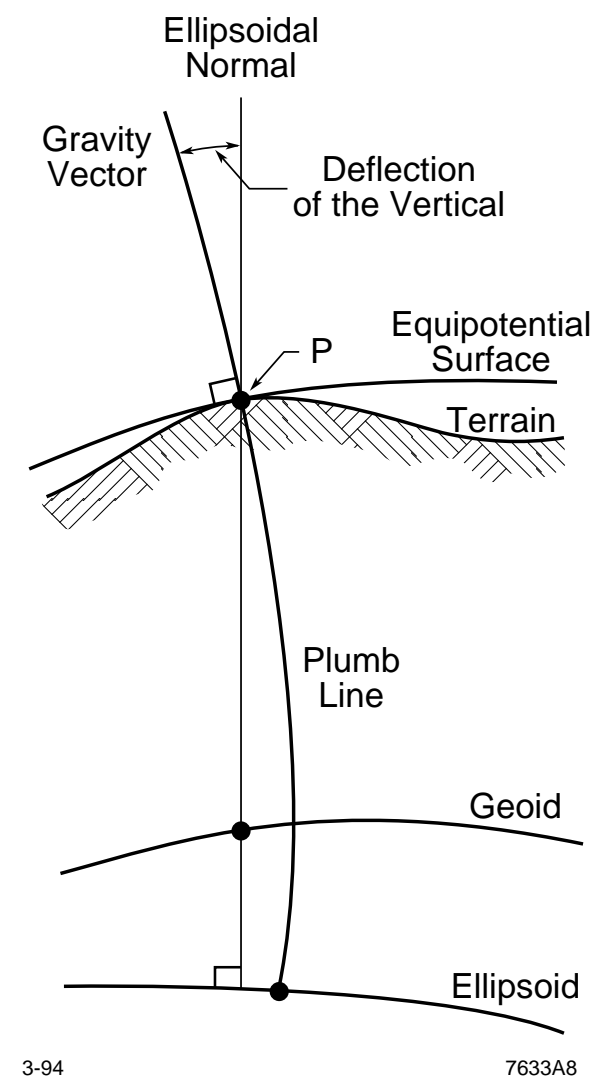

Fig. 23. Spheroid normal and gravity. 
spheroid that minimizes discrepancies only in the local area. Whatever ellipsoid is chosen, all survey measurements must be reduced to the ellipsoid before computations can proceed. This reduction of observations to the computational surface is an integral part of position determination; 18 the equations can be found in most of the geodetic literature, e.g., in Leick. ${ }^{19}$

\subsubsection{Surveying Coordinate System}

Computations with spheroidal (geographical) coordinates latitude $\phi$, longitude $\lambda$, and height $h$ are complex. They are also not very intuitive: when using spheroidal heights, it can appear that water is flowing uphill. Especially in survey engineering projects, coordinate differences should directly and easily translate into distances independent of their latitude on the reference spheroid. Therefore, it is desirable to project the spheroidal coordinates into a local Cartesian coordinate system or, going one step further, to project the original observations into the local planar system to arrive directly at planar rectangular coordinates.

A transformation is required to project points from a spheroidal surface to points on a plane surface. Depending on the projec-tion, certain properties of relationship (distance, angle, etc.) between the original points are maintained, while others are distorted. It is simply not possible to project a spherical surface on to a plane without creating distortions $^{18}$ (Fig. 24), but since these distortions can be modeled mathematically, it is possible to correct derived relationships, such as distances, angles, or elevations. This situation can be vividly
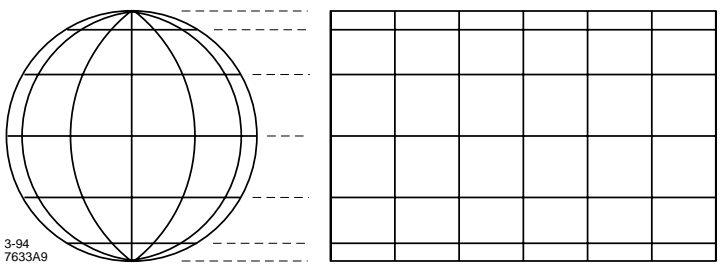

Fig. 24. Projection of sphere onto a plane. shown on the example of the projection of leveled elevations onto a planar coordinate system (Fig. 25). Table 1 shows the projection errors as a function of the distance from the coordinate system's origin. Notice that the deviation between plane and sphere is already $0.03 \mathrm{~mm}$ at $20 \mathrm{~m}$.

Since further discussion here is focused on small machines, geodetic issues such as the earth's curvature and gravity anomalies can be excluded, thus simplifying the mathematics to planar Cartesian coordinate arithmetic.

Table 1. Curvature correction, plane to sphere or spheroid.

\begin{tabular}{|c|c|c|}
\hline \hline $\begin{array}{c}\text { Distance } \\
{[\mathrm{m}]}\end{array}$ & $\begin{array}{c}\text { Sphere } \\
\mathrm{H}_{\mathrm{S}}[\mathrm{m}]\end{array}$ & $\begin{array}{c}\text { Spheroid } \\
\mathrm{H}_{\mathrm{E}}[\mathrm{m}]\end{array}$ \\
\hline \hline 20 & 0.00003 & 0.00003 \\
\hline 50 & 0.00020 & 0.00016 \\
\hline 100 & 0.00078 & 0.00063 \\
\hline 1000 & 0.07846 & 0.06257 \\
\hline 10000 & 7.84620 & 6.25749 \\
\hline 25000 & 49.03878 & 39.10929 \\
\hline \hline
\end{tabular}

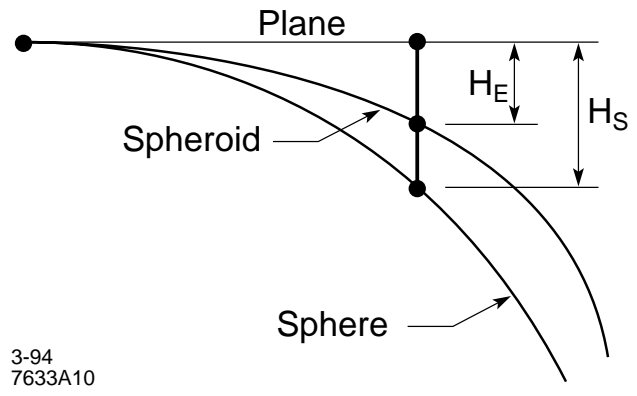

Fig. 25. Curvature correction. 


\subsubsection{Survey Networks}

The surveying coordinate system is physically represented by monuments whose coordinates are determined using conventional trilateration or triangulation methods or, for larger size projects, satellite methods like the Global Positioning System.20

Surface network In order to achieve the absolute tolerance and the circumference requirements, a surface network with pillar-type monuments (Fig. 26) must usually be established. Traditional triangulation and trilateration methods (Fig. 27) or GPS surveys can be applied to measure the coordinates of the monuments and of tripods over the transfer shafts or sightholes. Differential leveling of redundant loops is the standard method to determine the vertical coordinates. Proper reduction of measured distances also requires accurate elevation difference data.

Using state-of-the-art equipment in a small trilateration network with good intervisibility of monuments can yield standard deviations for the horizontal coordinates in the range of $2 \mathrm{~mm}+1 \mathrm{ppm}$. In medium size applications, it has been shown that GPS, combined with terrestrial observations and careful control of the antenna eccentricities (GPS, too, has its fiducialization problems), can yield positional accuracies of about $2 \mathrm{~mm} .{ }^{21}$ Trigonometric and differential leveling are the only accurate methods to determine elevations; both methods yield the same accuracies-approximately $1 \mathrm{~mm}$ for networks smaller than $2 \mathrm{~km}$.

Fig. 26. SLAC-SLC pillar monument. 


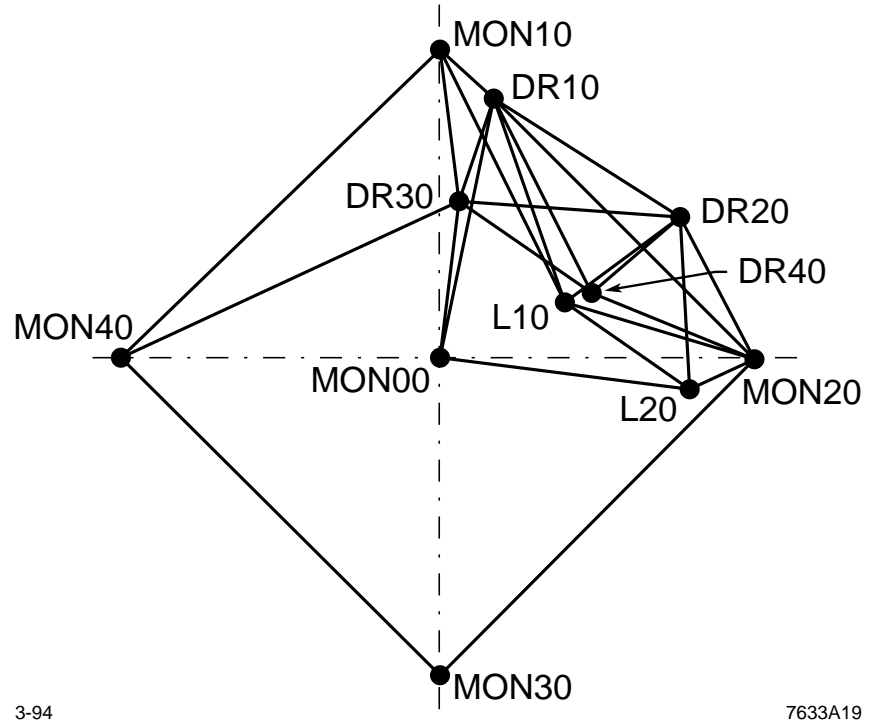

Fig. 27. Example of surface network (Argonne APS).
Tunnel The tunnel horizontal net is usually tied to the surface net by optically or mechanically centering a tripod-mounted translation stage on the surface over a monument in the tunnel through a survey shaft. These tunnel networks are usuallylong and narrow (Fig. 28), and incorporate points beneath the shafts as connections to the surface net. The floor marks can be 2-D (horizontal only) or 3-D: common designs are the SLAC 2-D marks, the DESY-HERA 3-D reference cups or the standard 1.5 inch floor cups and magnet mounts. Some

kind of tripod or column-like monopod is used for the instrument setup. The SLAC setup (Fig. 29) is designed to accommodate slopes of up to $15^{\circ}$; the HERA design is more optimized towards efficiency, virtually eliminating the task of centering instruments and targets over monuments. ${ }^{22}$ The elevation of the instrument above the 3-D reference cup is known very accurately, which facilitates 3-D mapping with theodolites.

\subsubsection{Layout Description Reference Frame}

The layout description of every machine component is given in a document called the design lattice (for details, refer to Chapter 2, Lattices) which defines the physical parameters of each machine component, including its ideal position.

For every new machine, various computer programs, e.g., TRANSPORT, ${ }^{23}$ are used to simulate the path of the particles. Model components bend, focus, or defocus the particles as they traverse the electromagnetic fields they encounter. Component parameters are manipulated to keep them on the intended trajectory, and to qualify the beam's characteristics. The result of such simulations is a sequential listing of the design components and their parameters. Most commonly, the parameters for the beginning of the magnetic length of a component and of the following drift space are listed, including the six degrees of freedom for the beam following coordinate system. In addition, a magnet's field strength, and, if applicable, its bending angle are given.

Based on experience and the results of lattice simulation runs, position tolerances are determined for each magnetic component and are attached to the lattice specifications

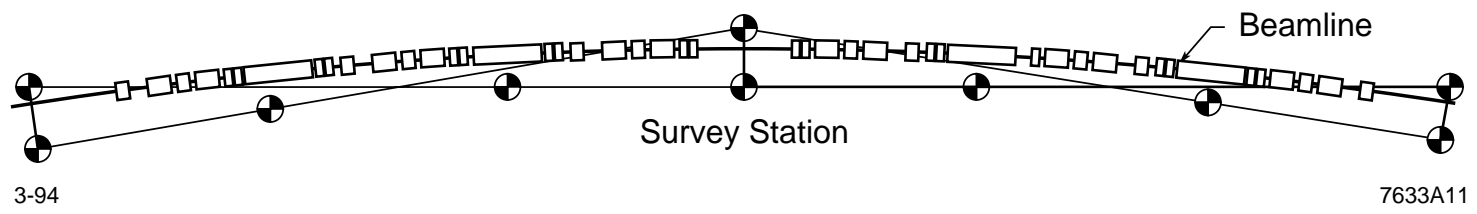

Fig. 28. Tunnel network layout (Argonne APS). 
Fig. 29. SLAC tripod setup.

(see Wiedemann ${ }^{24}$ for a discussion of the effects of magnet alignment errors). The individually specified parameters are usually the maximum permissible displacements in the direction of the three coordinates and the rotation around the longitudinal axis. The tolerance specifications should distinguish between absolute and relative positioning. The absolute positioning tolerance defines a maximum global shape distortion by specifying how close a component must be to its ideal location, whereas the more important relative tolerance defines the alignment quality of adjacent components. The tolerance definition should also state the required level of confidence, and whether or not the random distribution is truncated.

Surveying measurements, if done carefully with well-calibrated sensors, will show a typical Gaussian distribution, including entries outside the chosen confidence level. Achieving the equivalent of the mathematical truncation requires a means to identify "outliers" and a method to add independent redundant observations. Traditionally, the stochastic computations in surveying are based on a $1 \sigma$ confidence level. Achieving the same result on a $2 \sigma$ confidence level requires an exponential increase in survey effort.

The relationship between the surveying and lattice coordinate systems is defined as a transformation matrix. ${ }^{25}$

\subsubsection{Fiducialization}

Fiducialization is a fancy name for relating the effective internal electromagnetic axes of a component to external marks that can be seen or touched by instruments. It is these reference marks that are then aligned onto their nominal coordinates. It is therefore obvious that the measurement of the magnetic axis to the fiducial marks must be done with at least as much care as the final positioning. 
Fig. 30. Fiducialization setup of FFTB magnets at SLAC.

Magnets in storage rings and injection systems have, for the most part, been made with ferromagnetic poles, which are traditionally used as the references for exernal alignment fiducials. $^{26}$ (For more details, refer to Chapter 5, Magnet Design.) It is assumed that the magnetic field is well-defined by the poles, but this assumption fails in the presence of saturation, and is invalid for superconducting magnets, which have no tangible poles. Furthermore, since the poles of an iron dipole are never perfectly flat or parallel, where is the magnetic midplane?27 For quadrupoles, sextupoles, and higher order magnets, there is no unique inscribed circle that is tangent to more than three of these poles; where then is the centerline?

The only way to avoid these problems is to use magnetic field measurement (for details, refer to Chapter 7, Magnetic Measurements) to establish fiducials. This has already worked successfully for a number of projects, including the alignment of multiple permanent quadrupoles in drift-tube linac tanks in Los Alamos, ${ }^{28}$ the SLC/SLD superconducting triplet quadrupoles, the HERAsuperconducting proton ring magnets, ${ }^{29}$ and the Final Focus Test Beam at $\operatorname{SLAC}^{30}$ (Fig. 30).

\subsubsection{Prealignment of Girders}

Girders are commonly used in light sources to support components and the vacuum chamber of one lattice cell of a common plane. These girders are preassembled in a factory before they are transported into the tunnel. After an initial component prealignment, the magnets are split and the vacuum chamber inserted. The chamber can be positioned using 
gauge blocks held against the magnet pole tips, or optically. If no nonelastic girder deflections are expected during transportation, a fine position alignment is also made. $150 \mu \mathrm{m}$ is a typical tolerance for the relative positioning of magnets.

Usually, prealignment bays are set up emulating a generic beam line position; i.e., the girder is set up and supported in exactly the same way as it will be in its final beam line position. Traditional optical tooling techniques (Fig. 31) or industrial measurement system measurements (Fig. 32) can provide the required accuracy.

\subsubsection{Absolute Positioning}

Efficient computer-aided methods and procedures have been developed to increase positioning productivity, accuracy, and reliability. These techniques have been tested and proven in the alignment of many machines, including the ALS and APS light sources and the SLC, HERA, and LEP colliders. The absolute positioning can be subdivided into four steps :

Step 1. "Blue line" survey on the tunnel floor

Step 2. Rough absolute positioning of girders in tunnel

Step 3. Fine absolute positioning of girders

Step 4. Quality control survey

\subsubsection{Blue Line Survey on the Tunnel Floor}

In preparation for the installation of the support systems, a "blue line" survey is performed to lay out the anchor bolt positions. This is done from the tunnel traverse points using intersection methods or, more efficiently, utilizing tachymetry with instruments like the Leica TC2002 or the Chesapeake Lasertracker. ${ }^{31}$ A relative accuracy with respect to the monuments of $5 \mathrm{~mm}$ can be easily achieved.

Fig. 31. Prealignment with optical tooling (Argonne APS). Photo courtesy of Argonne National Lab. 
Fig. 32. Prealignment with industrial measurement system. Photo courtesy of Lawrence Berkeley Laboratory, University of California.

\subsubsection{Rough Absolute Positioning of Girders in Tunnel}

After the blue line survey, the anchors are set and the prealigned monoliths or girders installed, but with the anchor bolt nuts only "hand tight," and the girders' adjustment systems set to midrange to ensure the full adjustment range remains available for fine positioning. This adjustment system should not be used to correct the misalignment of the support system itself; instead, the support system is prealigned by tapping it into position utilizing the slack between anchor bolts and support structure. To determine the actual positions of the supports, direction and distance measurements from monuments are taken, from which actual coordinates are calculated and compared to the ideal coordinates, yielding the adjustment values in the global coordinate system orientation. Before these corrections can be applied in the field, they must be transformed into the local coordinate system of the supports. This process can be greatly accelerated by reducing the data on line in the field, providing immediate in situ coordinate feedback. High accuracy Total Stations, like the Leica TC2002 or the Chesapeake Lasertracker, interfaced to powerful field computers make this possible. The required software has been developed at SLAC and tested with great success in the alignment of the rebuilt SLC Damping Rings and Final Foci.

\subsubsection{Fine Absolute Positioning of Components}

The girders are first aligned vertically: using differential leveling, the girder is set to its ideal elevation with zero pitch and roll. The horizontal positions of the girders are set 
relative to the tunnel monument system. In principle, the alignment technique here is the same as described above. However, the TC2002 in the on-line feedback loop does not yield the required accuracy; only a laser tracker does. If a laser tracker is not available, traditional time-intensive triangulation techniques will effectively produce the same result.

\subsubsection{Quality Control Survey}

After the absolute positioning of girders is completed in some logically functional section of the machine, a complete resurvey of this section should be conducted to verify the results. Quality control is better achieved by the use of independent procedures, rather than the repetition of the same procedure by different teams. This provides the truly independent observations necessary to check the accuracy of the initial survey. Resurveys with the same methodology do not provide this independent check, and rarely detect the infrequent data gathering errors occurring with today's electronic instruments and field computers.

\subsubsection{Relative Positioning (Smoothing)}

The accuracy obtained in the absolute positioning step is the quadratic sum of many random errors (surface network, transfer of control through penetration shafts, tunnel control, magnet fiducia-

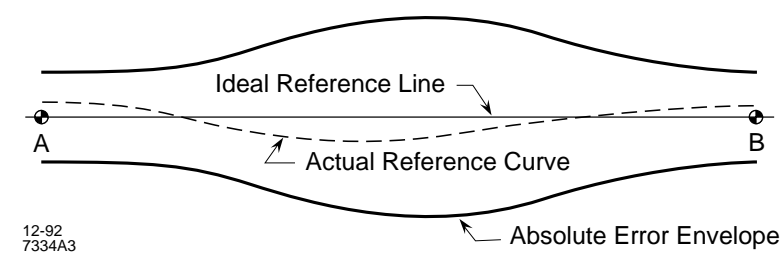

Fig. 33. Absolute positioning error envelope. lization, magnet layout, etc.) plus the linear sum of any residual systematic errors: instrument calibration, forced centering, set up over control points, velocity correction of light, horizontal and vertical refraction, etc. A cigar-shaped error envelope is typical for the absolute alignment of a beam line. (In this context, beam line refers to a section of a storage ring, and not to the tangential port which conveys the synchrotron radiation from the storage ring to the experimental station.) The error envelope is a minimum (but never zero) at the control points, and grows to reach a maximum midway between two successive control points (Fig. 33). The measured reference line oscillates somewhere within this error envelope. Its absolute position cannot be pinned down any more precisely than the size of the error envelope, with deviations within this envelope being statistically insignificant. However, within this absolute error envelope, relative errors between adjacent magnets should be smaller: the major error sources equally affect the positioning of adjacent components, with the result that relative alignment accuracies are significantly higher than absolute alignment accuracies. Consequently, successive surveys will reveal reference lines of different shape whose absolute position floats randomly within the cigarshaped error envelope. An important implication of this is that the absolute comparison of independent surveys "would be a nonsense" 32 when trying to evaluate differences smaller than the width of the absolute error envelope. If attempts are made to proceed with final absolute alignment, the "nonsense" occurs when successive rounds of survey and alignment do not converge, i.e., do not result in reducing the magnitude of the misalignments. All that is happening in this case is that the components are being moved back and forth within the error envelope. 

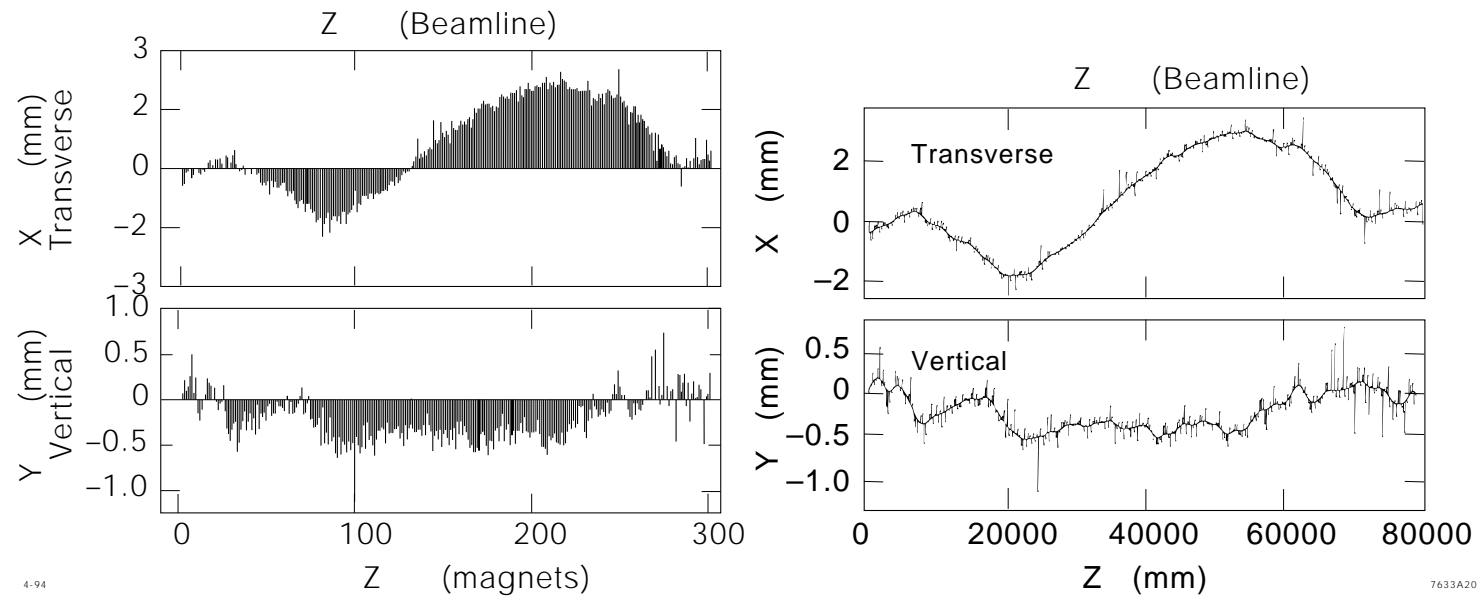

Fig. 34. Residual absolute misplacements.

Fig. 35. Trend curve through absolute misplacements.

Because of these problems, the absolute positioning technique is not well suited to achieving the final relative position tolerance. This problem was first recognized when the size of machines increased rapidly, stretching the distance between first-order monuments from $30 \mathrm{~m}$ (CERN-ISR) to $1200 \mathrm{~m}$ (CERN-SPS), and thereby magnifying and rendering visible this effect. To overcome the problem, techniques were developed to separate relative displacements from the absolute trend curve-techniques which we now refer to as "smoothing." After smoothing, the final distribution of residuals is examined by Fourier decomposition-type analysis to ensure that no significant amplitudes occur at the betatron frequency.

\subsubsection{SLAC-Style Smoothing}

The alignment tolerances set out for the SLC show how smoothness is more important than absolute positioning for beam transport. ${ }^{33}$ For this machine, a global positioning envelope is set to $\pm 5 \mathrm{~mm}$ for every arc magnet, while the relative alignment of three adjacent magnets should be within $\pm 0.1 \mathrm{~mm}$.

The pitched and rolled sausage-link beam line formed by the arc magnets makes this modeling particularly difficult. The absolute design shape of the path is a series of curves and straight sections in pitched and rolled planes. This form does not readily lend itself to fitting with polynomials or splines. The large coupling of the horizontal and vertical also prevents the separation of smoothing operations into two components.

The complication of an irregularly shaped beam line was eliminated by subtracting out the actual size and shape of the beam line, leaving a series of residual misplacements for a string of magnets (Fig. 34). Correlation between horizontal and vertical misalignments is removed using a spatial fitting routine. Principal Curve Analysis ${ }^{34}$ was chosen to simultaneously pass a one-dimensional curve through the horizontal and vertical residual misalignment mapped out along the $\mathrm{Z}$-axis (beam direction). This curve passes through the middle of the data set such that the sum of the squared errors in all variables is minimized (Fig. 35). The curve is nonparametric, with its shape suggested by the data.

The smoothing algorithm provides the options that make it possible to minimize movements of the magnets onto a smooth curve, and to identify outliers. If an outlier (e.g., erroneous measurement) exists, it may artificially bias the fitting routine and draw the curve 
curve away from the general neighborhood trend. For this reason, a robustness estimator is included in the modeling program to weight out these points.

One improvement was suggested through experience. This involved the independent weighting of points, so that a small area of magnets can be "patched in" to existing elements. Other improvements made it possible to deal with irregularly spaced and patterned beam line layouts.

\subsubsection{CERN-Style Radial Offset Smoothing}

The Super Proton Synchrotron (1971-76) presented major new challenges. The SPS was housed in an underground ring of $950 \mathrm{~m}$ radius. Six penetration shafts enabled the transfer of survey control from the geodetic network on the surface. The absolute error envelope ranged in size from $1.3 \mathrm{~mm}$ at each of the six control points to $2.5 \mathrm{~mm}$ midway along each $1152 \mathrm{~m}$-long sextant, far exceeding the $0.15 \mathrm{~mm}$ radial alignment tolerance. A procedure of radial smoothing was developed to achieve a relative alignment within this tolerance. Measurements were made directly from each magnet to adjacent magnets with no reference to the control monuments mounted on the tunnel walls ${ }^{35}$ (Fig. 36). This gave overlapping measurements of local curvature, which were then entered into a least-squares adjustment, minimizing the sum of squares of both the residuals and the radial offsets. 36 A relative alignment tolerance of about $0.08 \mathrm{~mm}$ was achieved using this method. Vertical alignment was undertaken as a separate process, using standard leveling practices for both absolute and relative vertical alignment. 37

The final alignment of the ESRF ring has been successfully achieved using the CERN method.

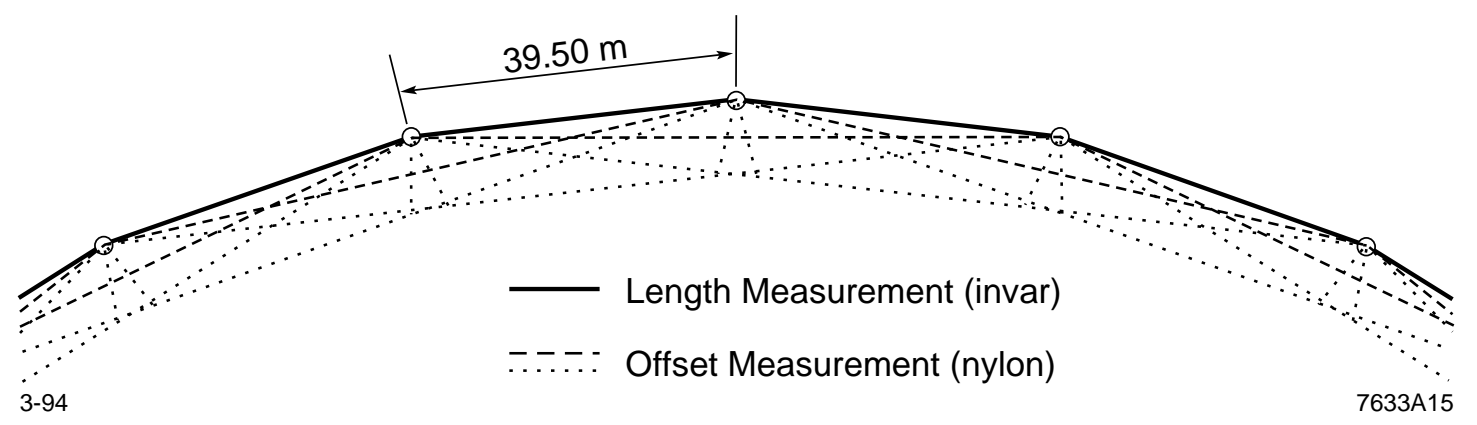

Fig. 36. Radial offset measurements.

\subsubsection{Survey and Alignment Toolbox}

Table 2 shows the progression through the typical contents of an accelerator surveyor's toolbox. The available space here does not allow a discussion of these tools. However, many surveying textbooks cover these instruments and software tools very competently. ${ }^{38-46}$

\subsection{Ground Motion}

Only in the last decade with the arrival of high-energy colliders and the third generation of light sources, have ground motion issues become significant and been studied. ${ }^{47-49}$ 
Table 2. Typical tools in an accelerator surveyor's toolbox.

\begin{tabular}{|l|c|}
\hline \hline Hardware tools & Software tools \\
\hline \hline Geodetic instruments & Integrated database \\
Theodolite & Data collection routines \\
Total station & Raw data reduction \\
Level & Analysis input merging \\
Plummet & Blunder detection \\
EDM & Network adjustments: \\
Distinvar & 1-, 2-, or 3-dimension \\
Distometer & Unconstrained datum \\
Optical tooling & Overconstrained datum \\
Jig transit & Graphical output \\
Spirit level & Coordinate database \\
Alignment telescope & Data analysis \\
Interferometry & Coordinate transformations \\
Photogrammetric equipment & Deformation analysis \\
Coordinate measuring machine & Shape fitting routines \\
Stationary & Special layout programs \\
Portable & Ideal coordinate calculation \\
Dial gauges & Alignment movements \\
Laser tracker & Smoothing routines \\
Industrial measurement system & On-line alignment control program \\
Forced centering system & Free stationing \\
Targeting systems & \\
\hline \hline
\end{tabular}

Ground motion is conveniently categorized into that due to nature and that due to man. Natural ground motion excites movements with long periods, seconds to years, while manmade ground motion, having far less energy content, is caused locally and generally has frequency components from a few to $50 \mathrm{~Hz} .^{50}$

\subsubsection{Natural Sources}

The main natural sources are:

- Ground settlement Every new construction project experiences some ground settlement. The effects can be minimized by building in areas of competent soil, by minimizing terrain disturbance, and by maintaining ground water levels.

- Tectonic motion Relative motion across a fault can reach several centimeters per year. Since almost all active faults are mapped, it should be possible to avoid these faults. However, there are still many unknown faults (e.g., fault lines discovered at SLAC during the Loma Prieta earthquake ${ }^{51}$ in 1989) that could generate ground motion effects at an unknown later time. 
- Earth tides The partially elastic body of the earth is deformed by the gravitational attraction of the moon and sun, causing diurnal and semidiurnal tides. The effects are always less than a decimeter and of very long wavelength. Today's light sources are too small for earth tides to be significant.

- Earthquakes Since severe earthquakes happen only relatively seldom, they need not be considered for the daily operation of a light source. However, site selection must evaluate the probability of potential seismic events and its effect on the design of structures.

- Ambient microseismic noise The main source for natural ambient microseismic noise is the coupling of ocean waves to the continents. Since the attenuation inland from the coasts is small, the effect is measurable throughout a continent.$^{52}$ Fischer and Morton ${ }^{53}$ calculate the time-averaged rms amplitude to reach about $1 \mathrm{~mm}$.

\subsubsection{Cultural Noise}

Local cultural noise is the dominant signal in the spectral region of a few hertz and above. Figure 37 shows the noise that is measured at DESY over the course of a week. ${ }^{54}$ The most common sources are:

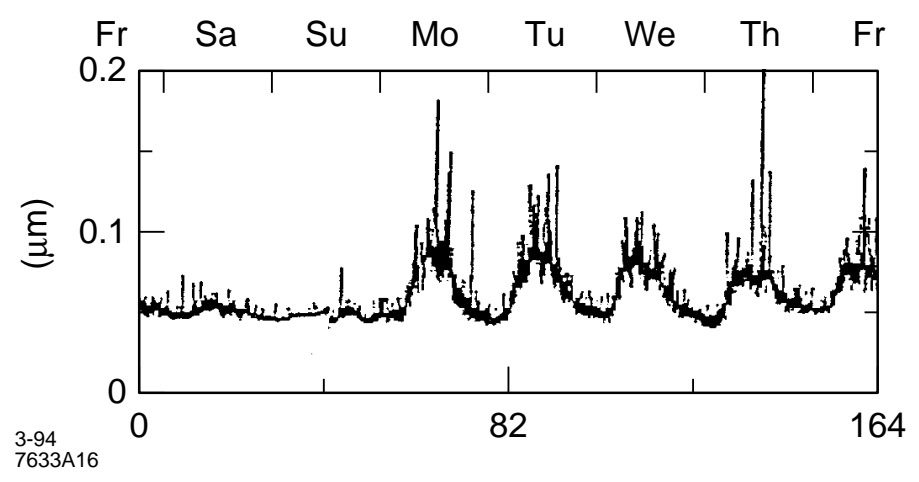

- Railroad traffic An object

Fig. 37. Cultural noise at DESY. as massive as a freight train traveling perhaps at speeds above $100 \mathrm{~km} / \mathrm{h}$ will couple some energy to the ground.

- Vehicle traffic, on-site and off-site Fischer and Morton ${ }^{56}$ report that auto and truck traffic produces disturbances at a tunnel level exceeding $0.5 \mu \mathrm{m}$. During site selection, it is therefore important to consider the existence and proximity of public streets, highways, and freeways.

- Continuously operating machinery Compressors, water pumps, fans, and especially all reciprocating machinery, contribute to the noise level of a site. Data given by Fischer and Morton ${ }^{57}$ shows that two $75 \mathrm{hp}$ vertical piston compressors operating at $6 \mathrm{~Hz}$ can produce a $1 \mu \mathrm{m}$ peak to peak motion at $30 \mathrm{~m}$. Appropriate isolation from the ground becomes very important.

\subsubsection{Countermeasures}

\subsubsection{Prevention}

The best countermeasure to ground motion is prevention. First of all, the machine should be designed to make it less sensitive to the positional stability of its components. Secondly, adherence to good engineering and housekeeping principles will prevent, or at least minimize, the effects of traffic noise and of reciprocating machinery. Thirdly, it is 
important "to prevent politicos from choosing sites that are severely beset by natural and man-made disturbances." 58

\subsubsection{Active Countermeasures}

- Vibration isolation Fast ground motion can be dampened and significantly reduced with active isolation. ${ }^{58-60}$ Ishihara reported that a table was kept stable to $50 \mathrm{~nm}$ against a sine wave disturbance with $500 \mathrm{~nm}$ amplitude and frequency up to $50 \mathrm{~Hz} .61$ Such a system was incorporated into the FFTB at SLAC to stabilize the quadrupoles at the interaction point.

- Dynamic alignment system Slow frequency ground motion can be compensated for by dynamic alignment systems. A first step towards a dynamic system was made at the ESRF with the development and deployment of the automated hydrostatic level system and the remotely controlled vertical jacks (see Section 11.1.3 above). A first truly dynamic alignment system for vertical and lateral alignment was implemented in the FFTB at SLAC. ${ }^{62}$ First commissioning results indicate that the system can maintain the alignment to a few microns over the course of weeks.

- Feedback on beam derived information Feedback systems have always helped to overcome the dilemma of not meeting tolerances. Hettel reports a successful application at SSRL. ${ }^{63}$ However, there are limitations to the application of beam derived intelligence. Fischer warns that "the proliferation of feedback systems will, if not held in check, lead to increasing inoperability since each system adds another layer of complexity." 64

- Feedforward on beam derived information Since the low-frequency disturbances of an orbit derive primarily from quadrupole magnet vibrations of a certain dominant mode, a scheme was developed to compensate for the quadrupoles' vibration movements. Seismic accelerometers measure the magnets' vibrations and drive the compensation current into the quadrupoles' trim coils accordingly. Yao reports better than $99 \%$ canceling of field shaking due to $10 \mu$ m magnet vibrations. 65

\section{Acknowledgments}

I would like to thank all the individuals at the universities and accelerator laboratories around the world who shared their ideas and experience with me. The section on magnet supports would not have been possible without the positive response to my request for local support system design examples: thank you to Gordon Bowden, SLAC; Horst Friedsam, APS; Ted Lauritzen, ALS; Michel Mayoud, CERN; Will Oren, CEBAF; Willfried Schwarz, DESY; and Rick Wilkins, SSC. Special thanks to Bernard Bell for painstakingly reading the manuscript. 


\section{References}

1. Ted Lauritzen, "The ALS Six Strut Support System," presentation at the Pohang Light Source Laboratory (Pohang, September 1992), p. 4.

2. Conceptual Design Report, 1-2 GeV Synchrotron Radiation Source (Lawrence Berkeley Laboratory, Berkeley, July 1986), p. 77.

3. Anocast, a Division of Anorad Corp., 110 Oser Ave., Hauppauge, NY 11788.

4. Ted Lauritzen, private communication.

5. Michel Mayoud, private communication.

6. George Biallas, private communication.

7. Charles Perkins, private communication.

8. Bill Davies-White, private communication.

9. Michel Mayoud, private communication.

10. Dieter Walz, private communication.

11. Willfried Schwarz, private communication.

12. Gordon Bowden, private communication.

13. A. Bergamin et al., "Servopositioning with Picometer Resolution," Rev. Sci. Instrum. 64 (1993) 168-173.

14. E. Furse, "Kinematic Design of Fine Mechanisms in Instruments," Phys Sci. Instrum. 14 (1981) 264-271.

15. Daniel Roux, "Alignment \& Geodesy for the ESRF Project," in Proc. First Int. Workshop on Accel. Alignment (SLAC, Stanford, 1989), SLAC-375, p. 37.

16. Daniel Roux, "The Hydrostatic Leveling System (HLS)/Servo-Controlled Precision Jacks-A New Generation Altimetric Alignment and Control System," in Proc. Particle Accel. Conf. (Washington DC, 1993), pp. $29321 \mathrm{f}$.

17. John E. Jackson, Sphere, Spheroid and Projections for Surveyors, (Granada, London 1980), p. xi; Petr Vaníchek and E. Krakiwsky, Geodesy-The Concepts, (Elsevier, Amsterdam, 1986), pp. 1-8, 110.

18. Jackson, op. cit., p. 84.

19. Alfred Leick, GPS Satellite Surveying, (John Wiley \& Sons, New York, 1990), p. 188.

20. Clyde C. Goad, "Precise Positioning with the GPS," in Applied Geodesy for Particle Accelerators, (CERN Accelerator School, CERN 87-01, Geneva, 1987), p. $36 \mathrm{ff}$.

21. Robert Ruland and A. Leick, "Application of GPS in a High Precision Engineering Survey Network," in Proc. First Symp. on Precision Positioning with GPS (Rockville, MD, 1985), p. 483ff.

22. Franz Löffler and W. Schwarz, "The Geodetic Approach for HERA," in Proc. First Int. Workshop on Accelerator Alignment (Stanford, 1989), SLAC-375, p. 117.

23. By "Transport," we mean the generic computer code that performs the ion-optical simulation.

24. Helmut Wiedemann, Particle Accelerator Physics, Basic Principles and Linear Beam Dynamics (Springer Verlag, Berlin, 1993), pp. 226-228. 
25. Will Oren and R. Ruland, "Survey Computation Problems Associated with MultiPlanar Electron-Positron Colliders," in Proc. 45th ASP-ACSM Convention, (Washington, DC), pp. 338-347; and SLAC-PUB-3542.

26. Horst Friedsam et al., "Magnet Fiducialization with Coordinate Measurement Machines," in Proc. First Int. Workshop on Accelerator Alignment (SLAC, Stanford, 1989), SLAC-375, p. 206ff.

27. Alex Harvey, "The Magnet Fiducialization Problem," ibid., p. 200.

28. Cliff M. Fortgang et al., "Pulsed Taut-Wire Alignment of Multiple Permanent Magnet Quadrupoles," in Proc. 1990 Linear Accel. Conf. (Albuquerque, 1990), p. 48.

29. Franz Löffler, "Referencing the Magnetic Axis for HERA's Superconducting Magnets," in Proc. First Int. Workshop on Accelerator Alignment (SLAC, Stanford, 1989), SLAC-375, p. 232.

30. Gerhard E. Fischer et al., "Finding the Magnetic Center of a Quadrupole to High Resolution," ibid., p. 213

31. Robert Ruland, "The Chesapeake Laser Tracker in Industrial Metrology," in Proc. Third Int. Workshop on Accel. Alignment (Annecy, 1993), pp. I/101ff.

32. Michel Mayoud, op. cit., p. 138.

33. Horst Friedsam, W. Oren, "The Application of the Principal Curve Analysis Technique to Smooth Beam Lines," in Proc. First Int. Workshop on Accelerator Alignment (SLAC, Stanford, 1989), SLAC-375, pp. 152-161.

34. Trevor Hastie, Principal Curve Analysis, SLAC-276, 1984.

35. Michel Mayoud, "Geodetic Metrology of Particle Accelerators and Physics Equipment," in Proc. First Int. Workshop on Accelerator Alignment (SLAC, Stanford, 1989), SLAC-375, p. 138.

36. Mayoud, ibid., and private communication.

37. Jean Gervaise, "Applied Geodesy for CERN Accelerators," Seminar on HighPrecision Geodetic Measurements (University of Bologna, 1984).

38. Fritz Deumlich, Surveying Instruments (de Gruyter, Berlin, 1982).

39. Peter Richardus, Project Surveying (A.A. Balkema, Rotterdam, 1984).

40. Grün/Kahmen, eds., Optical 3-D Measurement Techniques II, (Wichmann, Karlsruhe, 1993).

41. J. Uren and W.F. Price, Calculations for Engineering Surveys (Van Nostrand Reinhold, Wokingham, 1984).

42. Fritz Hennecke et al., Handbuch Ingenieurvermessung (Wichmann, Karlsruhe, 1988).

43. Heribert Kahmen and Wolfgang Feig, Surveying (de Gruyter, Berlin, 1988).

44. J.M. Rüeger, Electronic Distance Measurement (Springer-Verlag, Berlin, 1990).

45. Ted Busch, Fundamentals of Dimensional Metrology (Delmar Publishers, New York, 1966). 
46. Philip Kissam, Optical Tooling for Precise Manufacture andAlignment (McGraw-Hill, New York, 1962).

47. Helmut Wiedemann, "Tolerances on the Dynamic Stability of Ring Components," ESRP Internal Report ESRP-IRM-81/84 (Oct. 1984).

48. T. Aniel and J.L. Laclare, Sensitivity of the ESRP Machine to Ground Movement, Saclay LNS/086, January 1985.

49. Gerhard E. Fischer, "Ground Motion and its Effects in Accelerator Design," 1984 Summer School Lecture at FNAL, SLAC-PUB-3392R (July 1985).

50. Gerhard E. Fischer and P. Morton, "Ground Motion Tolerances for the SSC," SLAC-PUB-3870, SSC-55 (1986).

51. Robert Ruland, "A Summary of Ground Motion Effects at SLAC Resulting from the Oct. 17th Earthquake," in Proc. Second Int. Workshop on Accel. Alignment (Hamburg, 1990), pp. 131-156.

52. K. Aki and P. Richards, Quantitative Seismology (Freeman and Co., 1980) Vol. 1, Ch. 10.

53. Fischer and Morton, op.cit., p. 9.

54. Jürgen Rossbach, HERA Errors and Related Experiments during Commissioning, DESY HERA 91-21 (1991).

55. Fischer and Morton, op.cit., pp. 14-16.

56. Fischer and Morton, op.cit., p. 17.

57. Gerhard E. Fischer, "Ground Motion - An introduction for Accelerator Builders," Proc. CERN Accelerator School, Magnetic Measurement and Alignment (Montreux, 1992); and SLAC-PUB-5756.

58. W. Ash, "Final Focus Supports for a TeV Linear Collider," SLAC-PUB-4782 (1988).

59. N. Ishihara et al., "A Test Facility of Active Alignment System at KEK," in Proc. First Int. Workshop on Accelerator Alignment (SLAC, Stanford, 1989), SLAC375, p. 73ff.

60. M. Naganoh et al., "Active Control Microtremor Isolation Systems," ibid., p. $287 \mathrm{ff}$.

61. Ishihara et al., op.cit., p. 76.

62. Robert Ruland, "A Dynamic Alignment System for the Final Focus Test Beam," in Proc. Third Int. Workshop on Accel. Alignment, (Annecy, 1993), p. $241 \mathrm{ff}$.

63. R. O. Hettel, "Beam Steering at the Stanford Synchrotron Radiation Laboratory," IEEE NS-30, 4, (1983), p. 2228ff.

64. Gerhard E. Fischer, "Alignment and Vibration Issues in TeV Linear Collider Design," in Proc. First Int. Workshop on Accelerator Alignment (SLAC, Stanford, 1989), p. 284; and SLAC-PUB-5024.

65. Cheng Yao, "Compensation of Field Shaking due to the Magnet Vibration," in Proc. Particle Accel. Conf. (Washington, 1993), p. 1393ff. 


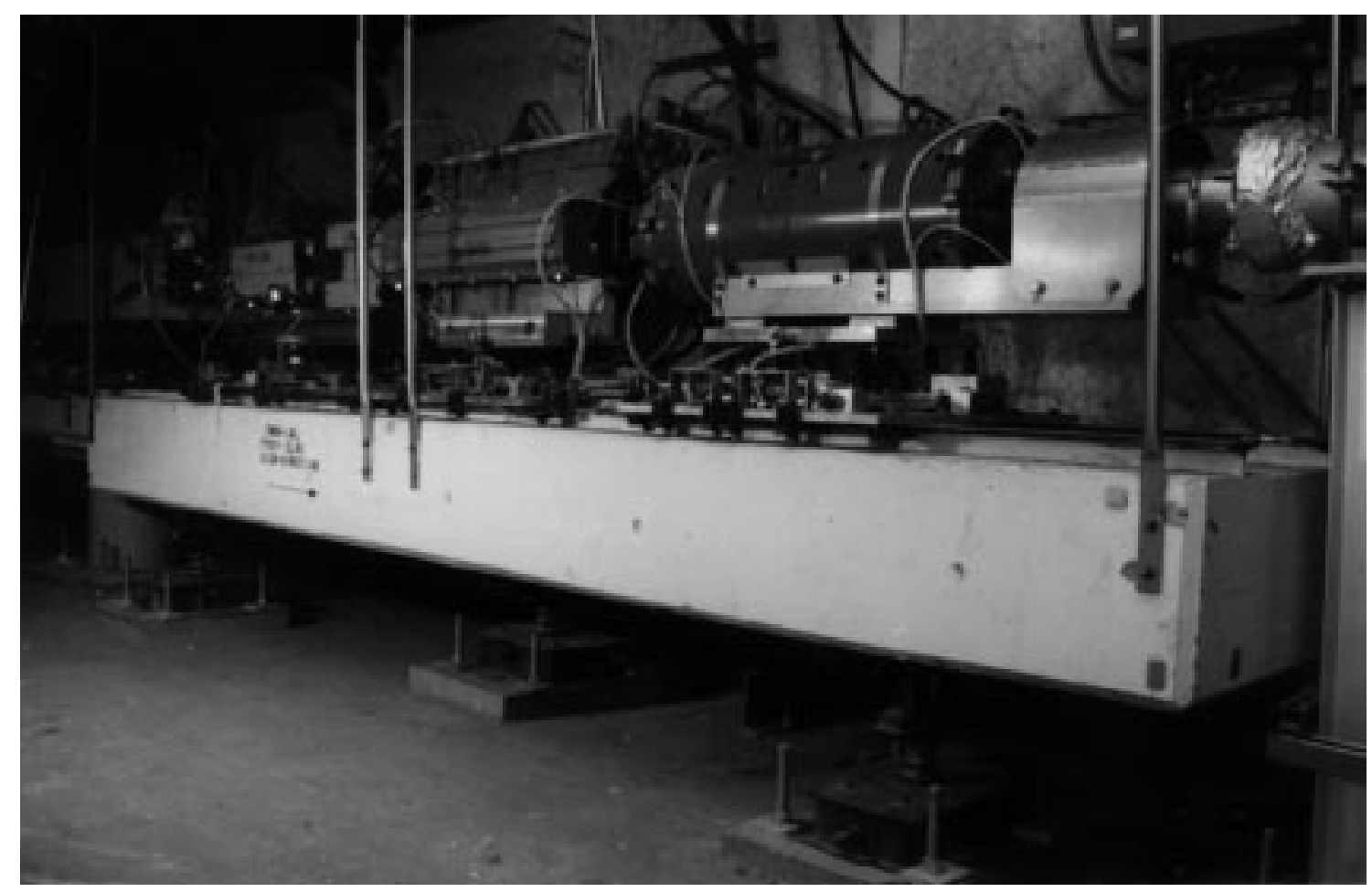

Fig. 1. Concrete girder as used in SLAC Final Focus. 


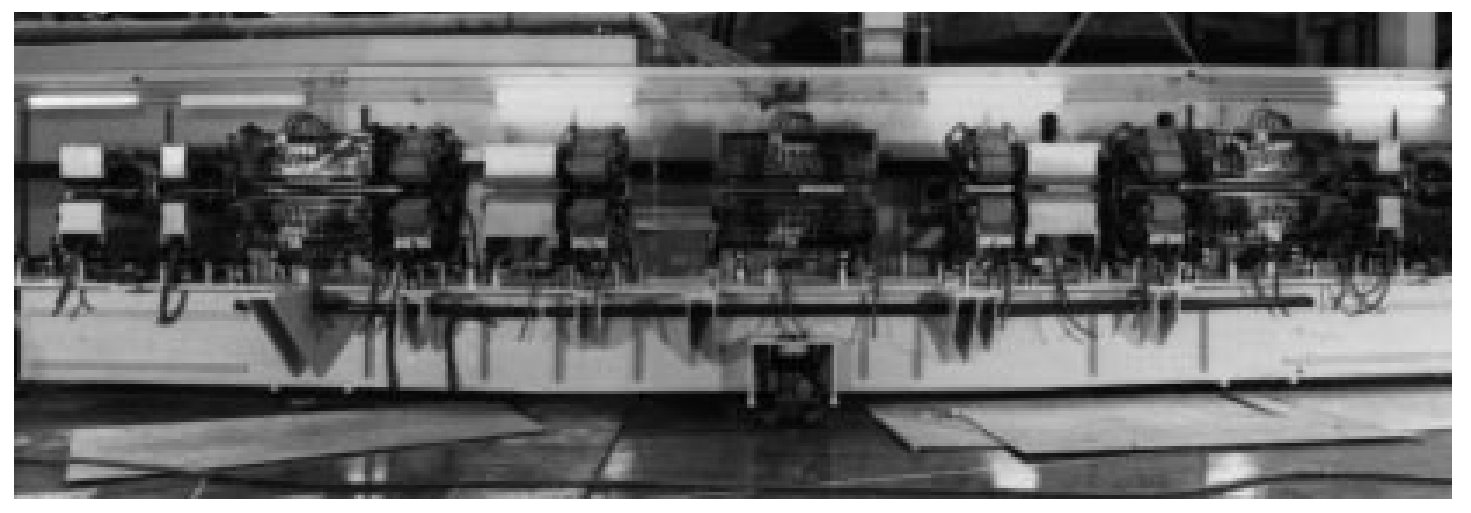

Fig. 2. Steel girder as used in LBL ALS. Photo courtesy of Lawrence Berkeley Laboratory, University of California. 


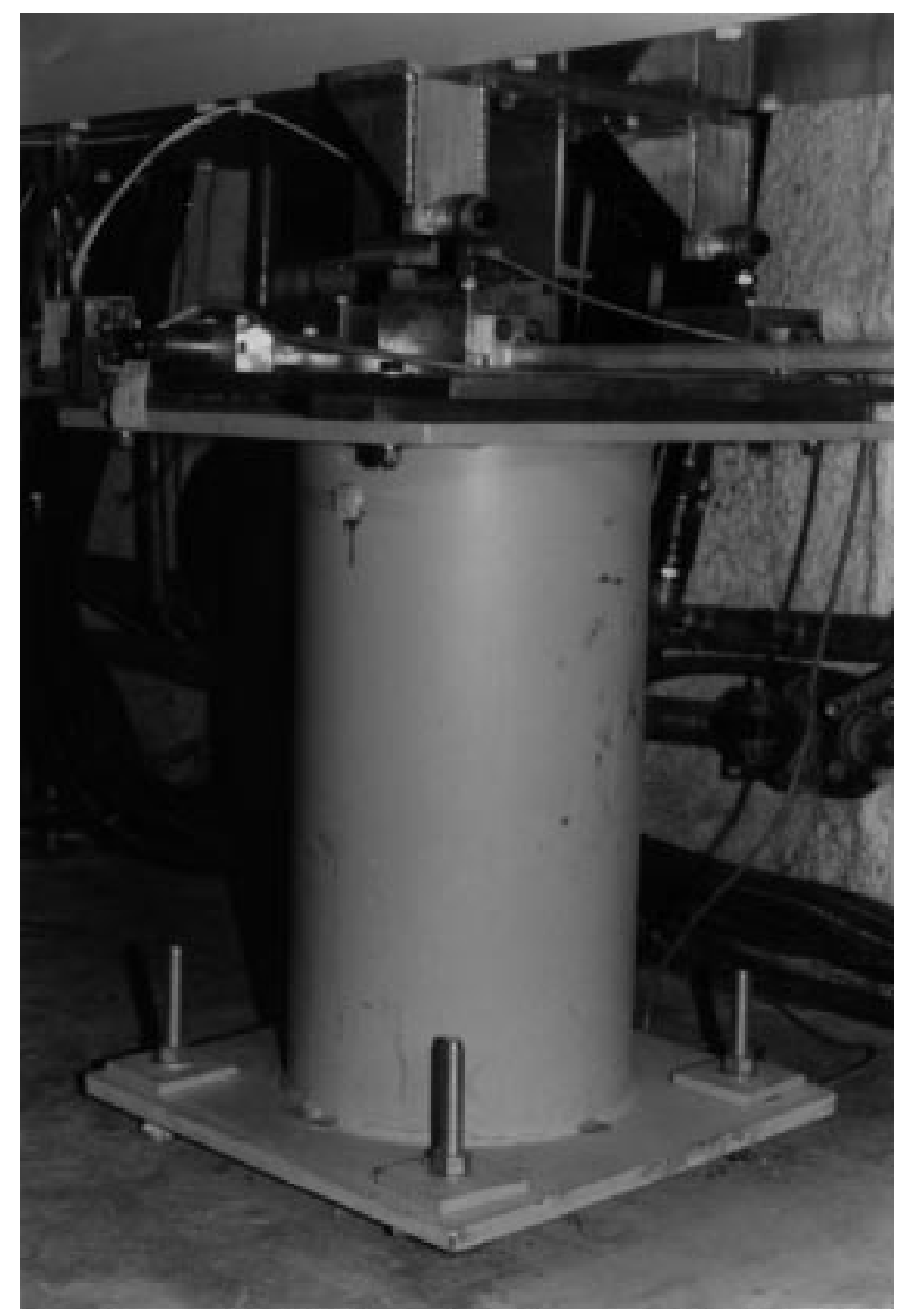

Fig. 3. Individual steel stand. 

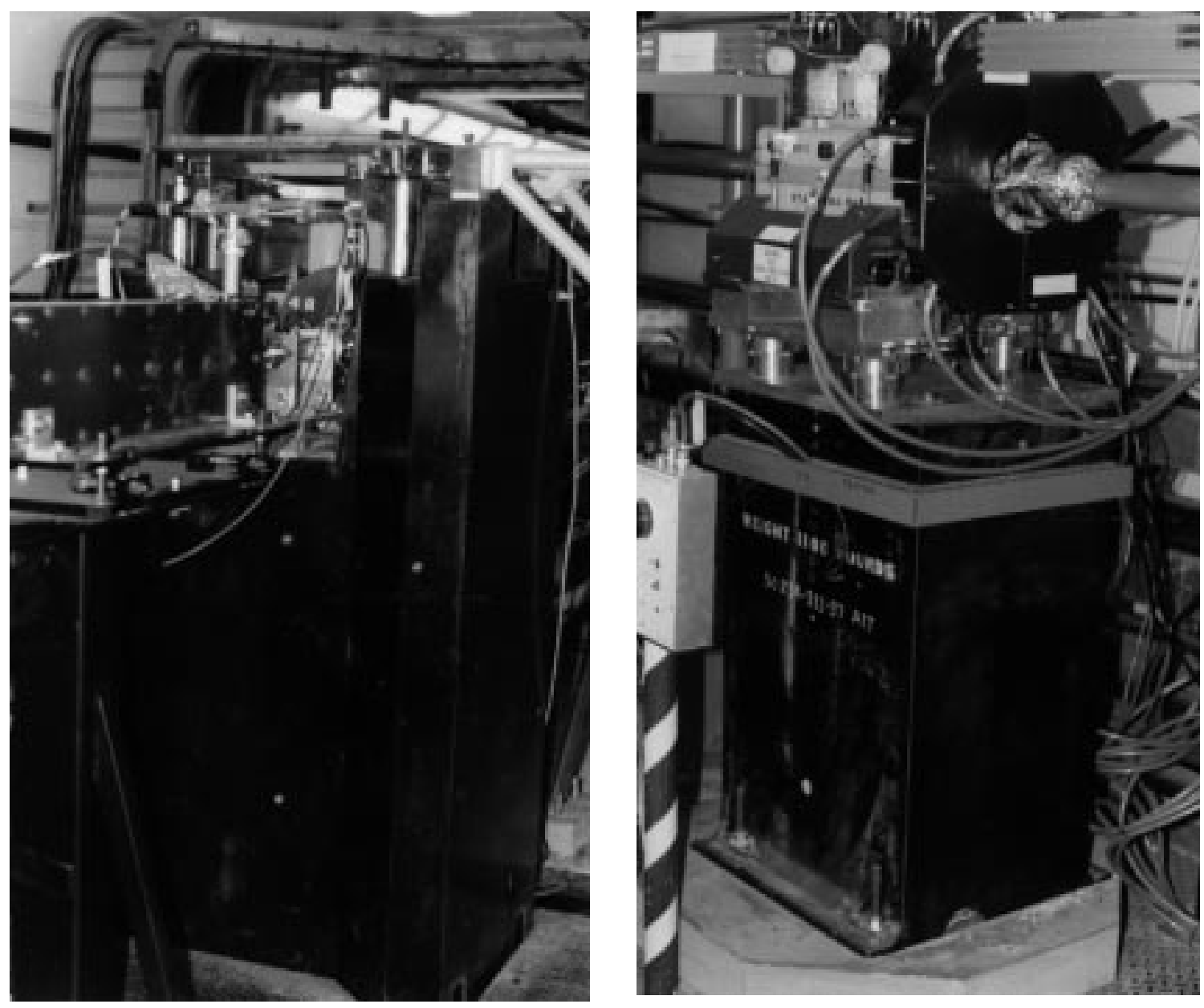

Fig. 4. Anocast stand in SLAC FFTB. 


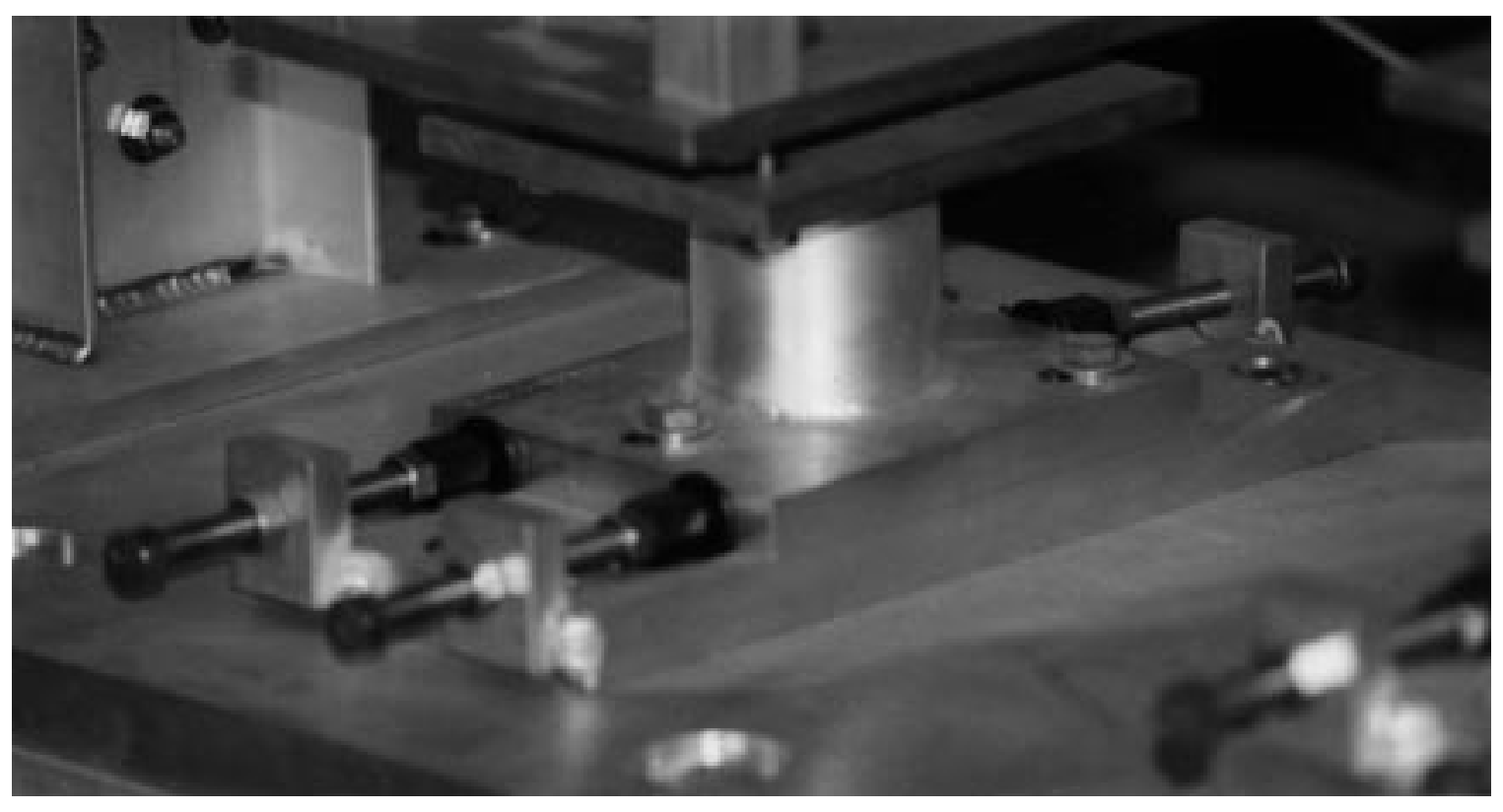

Fig. 5. Push-push screw arrangement. 


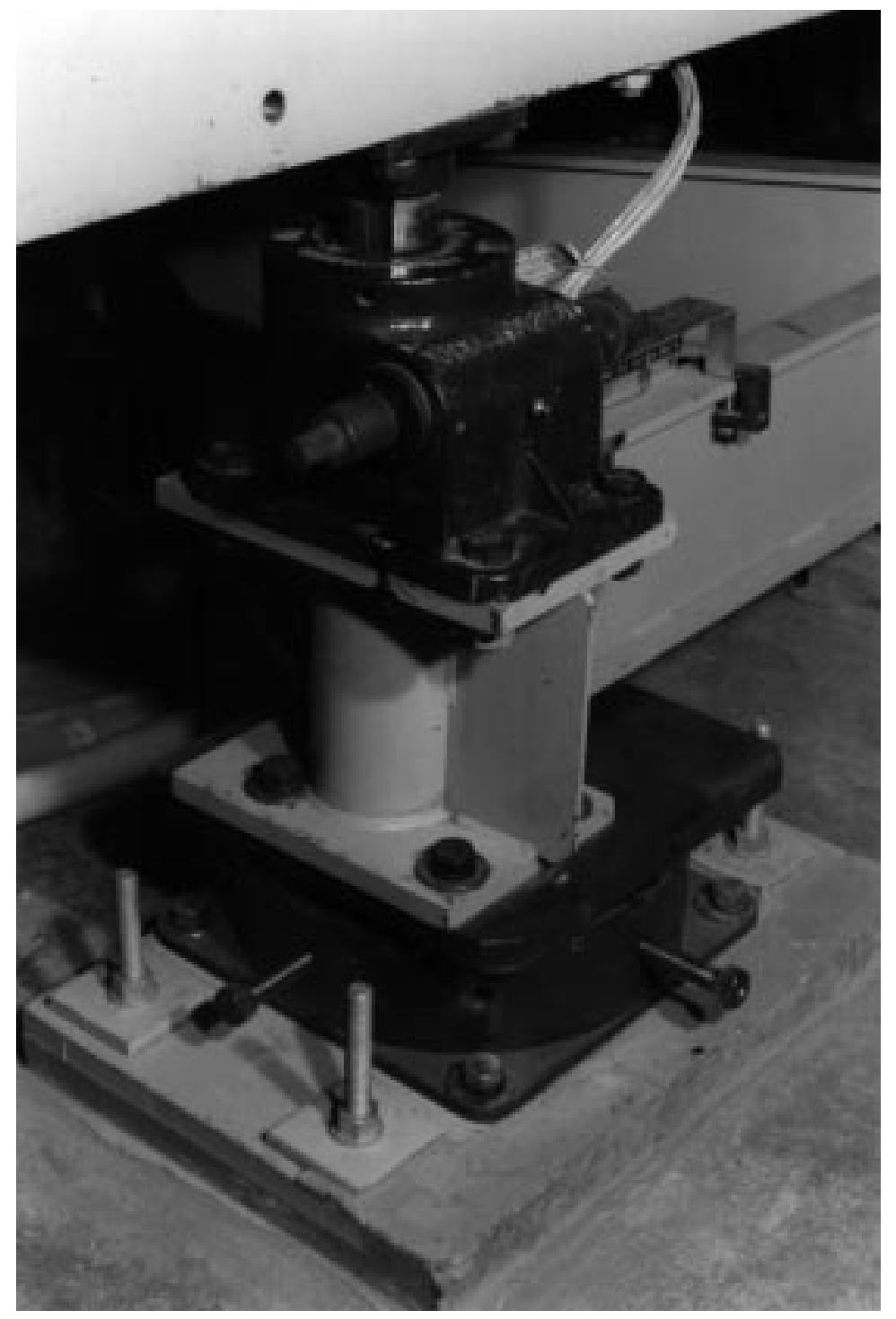

Fig. 6. Machine screw jack support. 


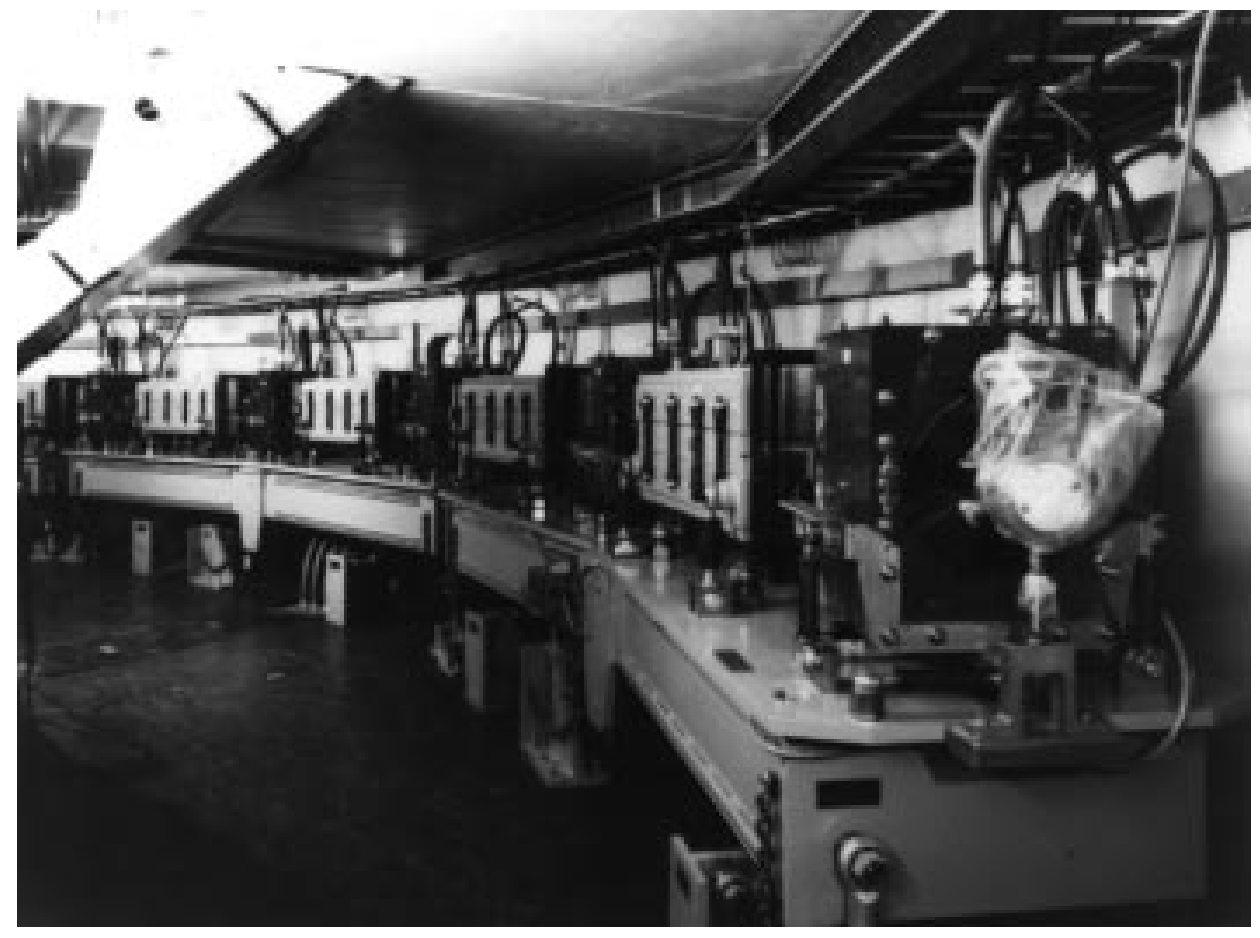

Figure 9. ALS strut supports. Photo courtesy of Lawrence Berkeley Laboratory, University of California. 


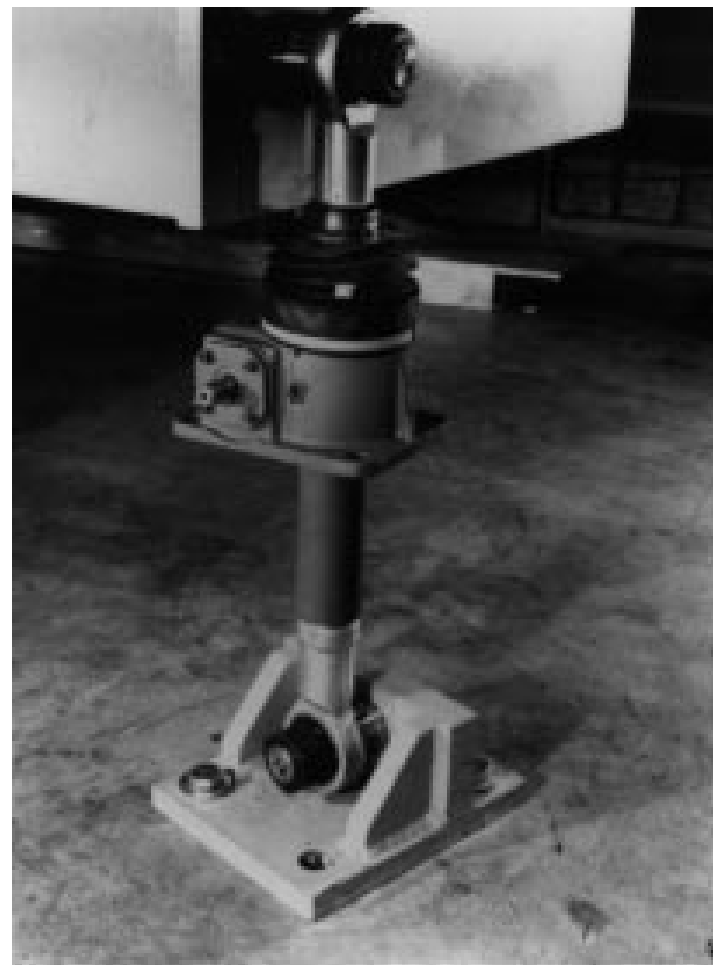

Fig. 10. ALS 5-ton machine screw jack strut. Photo courtesy of Lawrence Berkeley Laboratory, University of California.

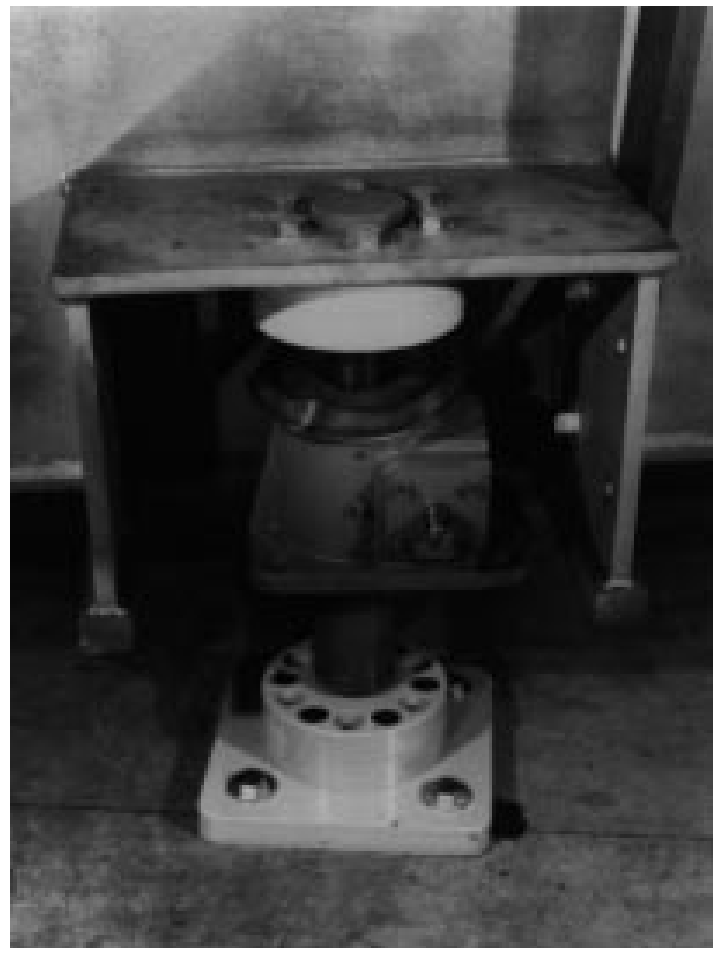

Fig. 11. ALS 20-ton machine screw jack strut.

Photo courtesy of Lawrence Berkeley Laboratory, University of California. 


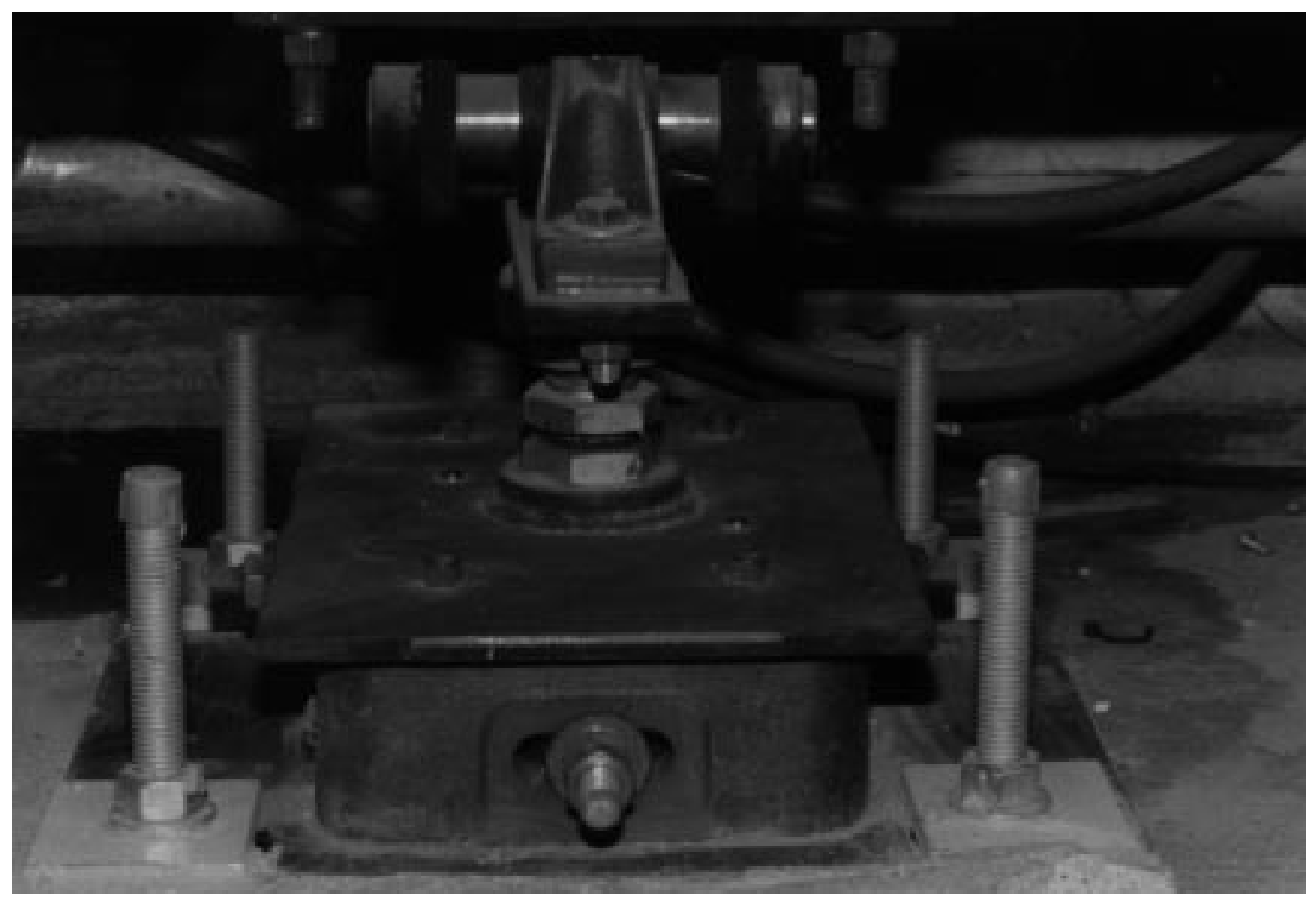

Fig. 15. SLAC Final Focus girder support. 


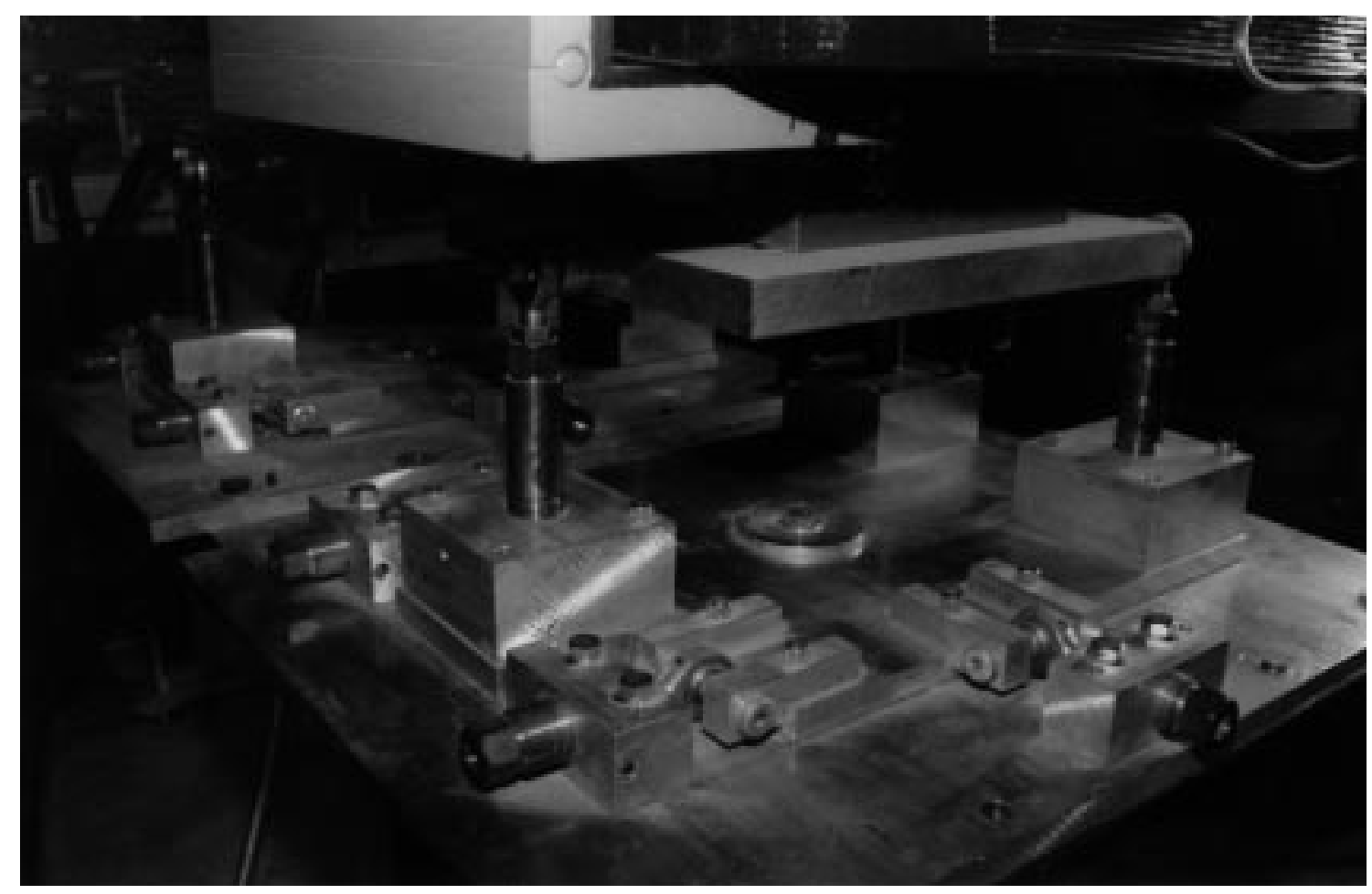

Fig. 17. SLAC 3-D stage. 


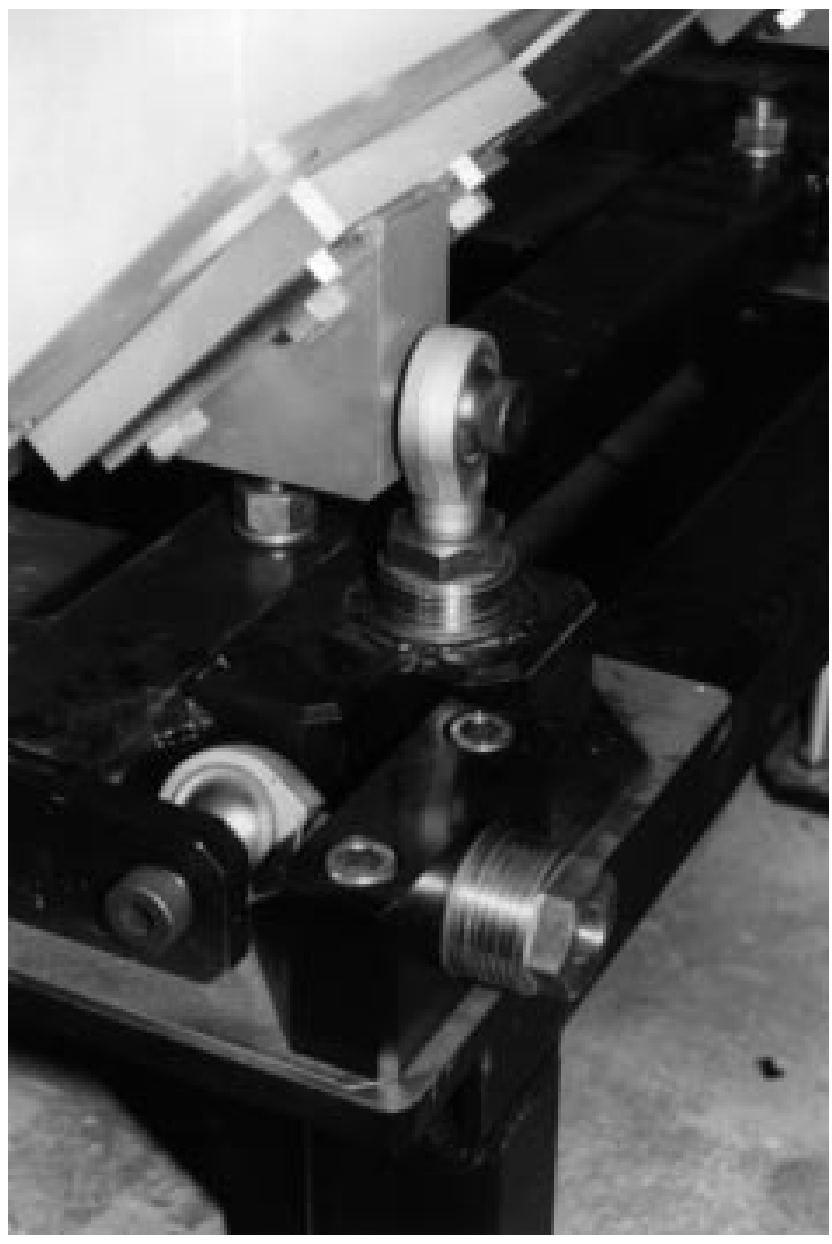

Fig. 18. Lateral adjustment layout. 


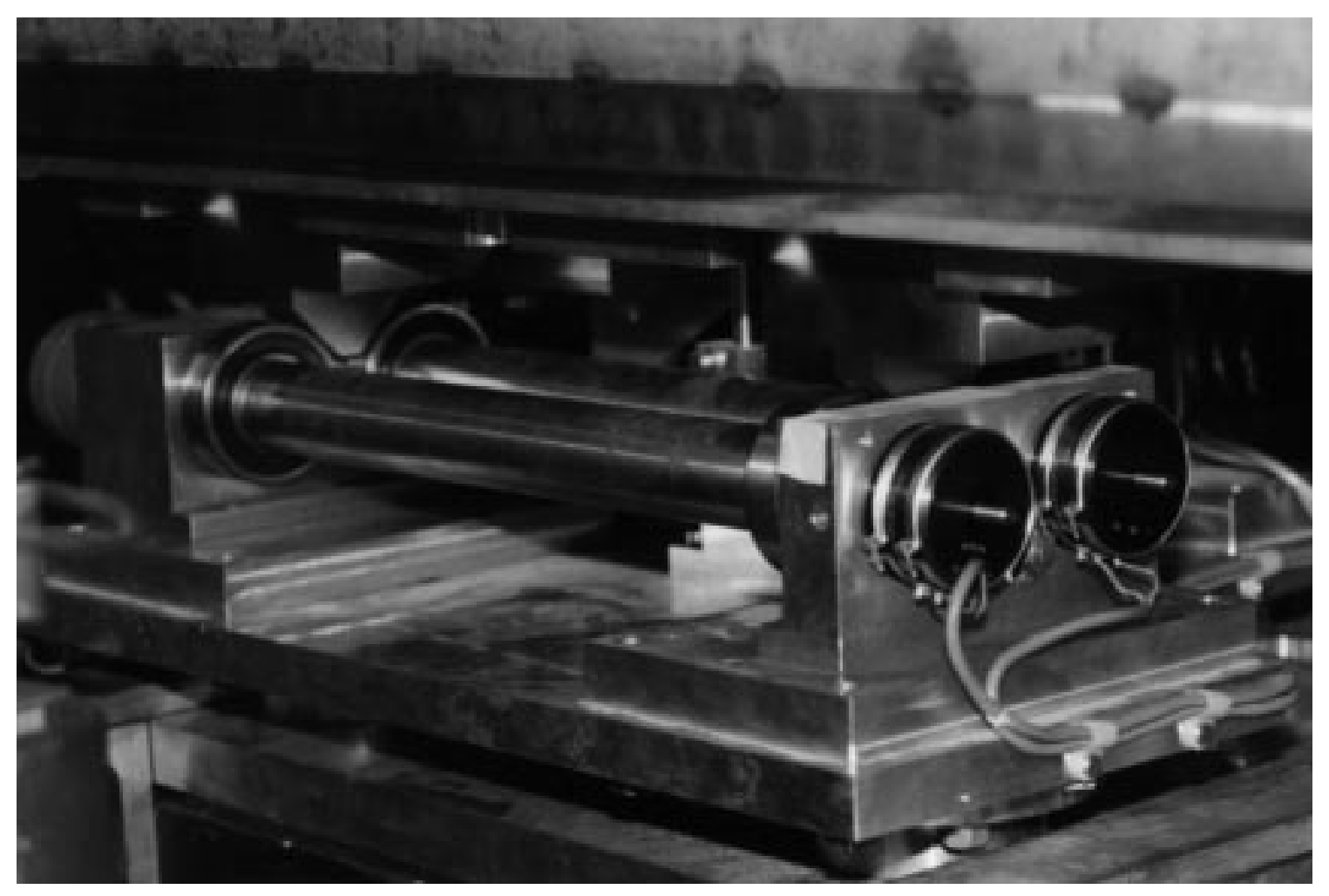

Fig. 21. FFTB magnet remote positioner. 


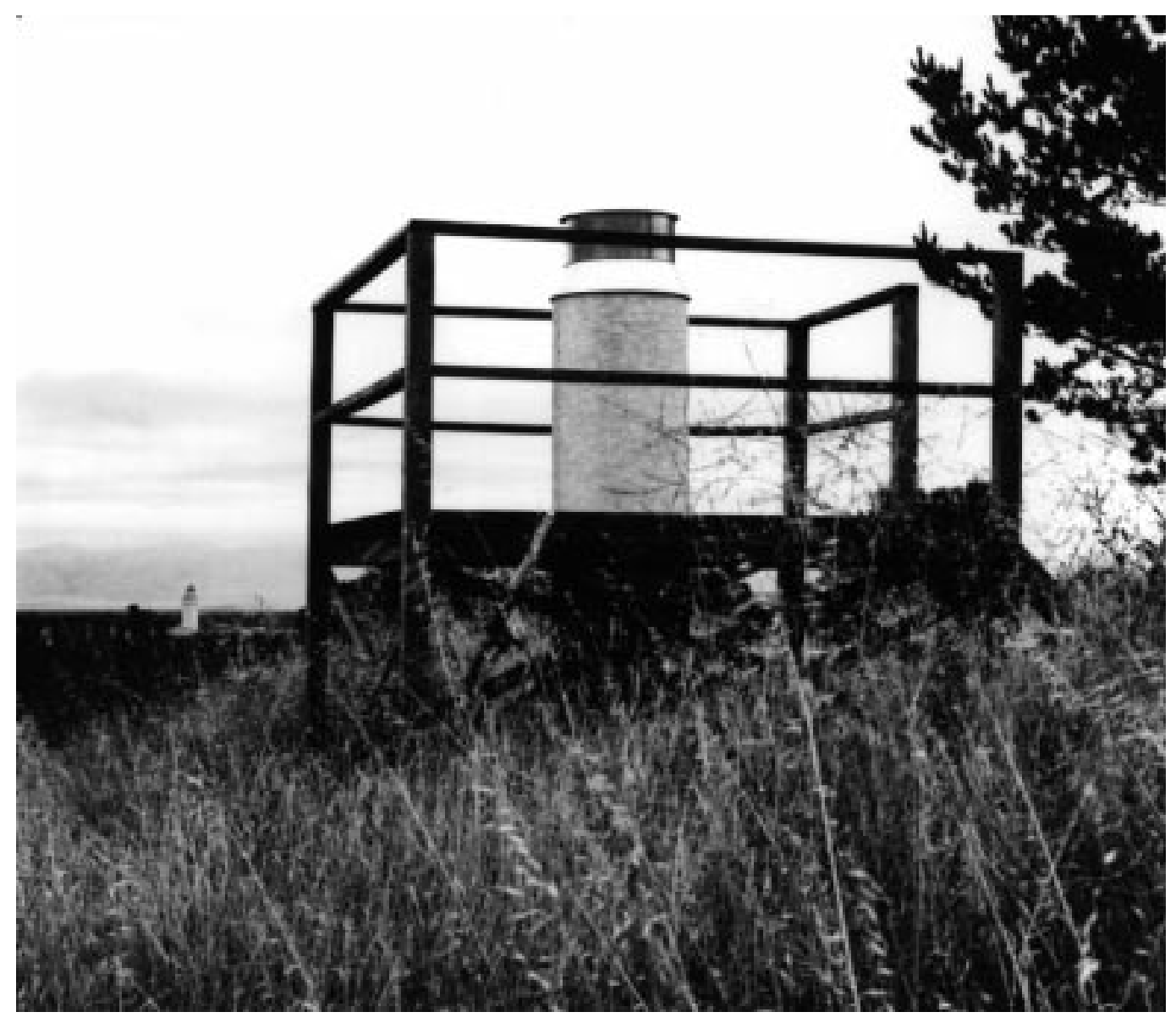

Fig. 26. SLAC-SLC pillar monument. 


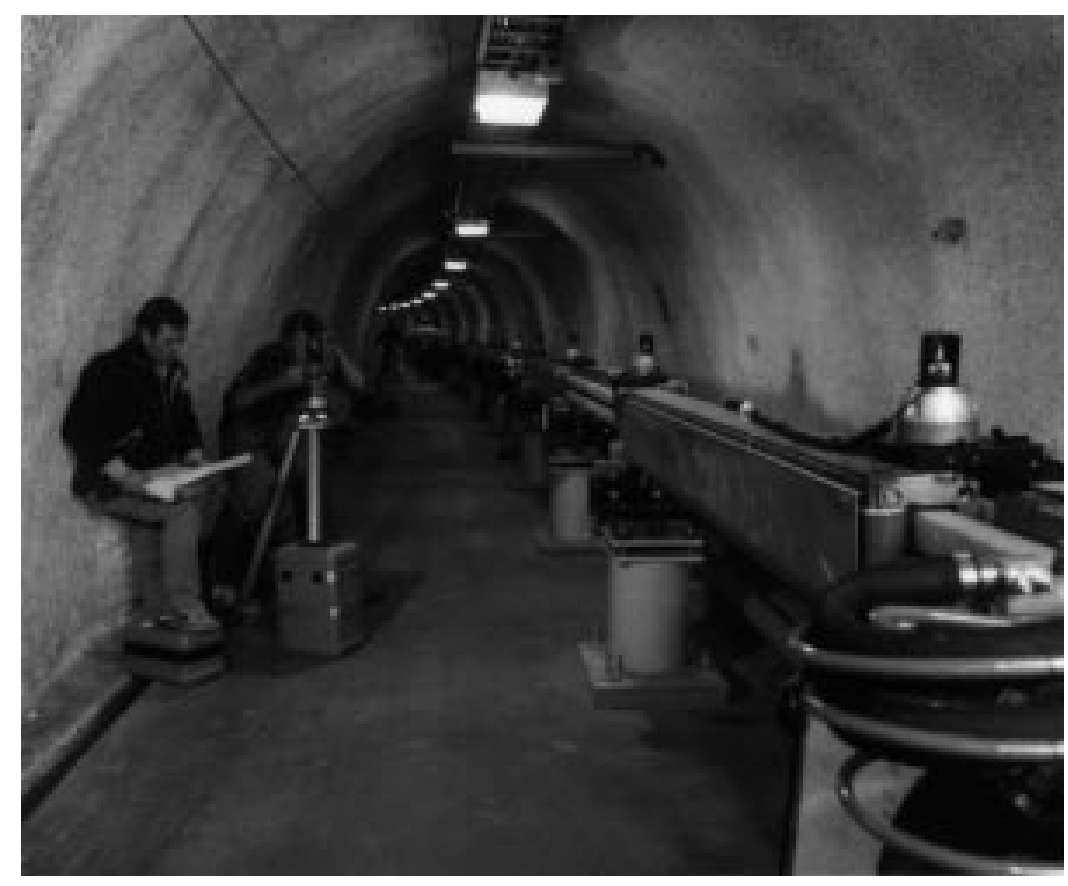

Fig. 29. SLAC tripod setup. 


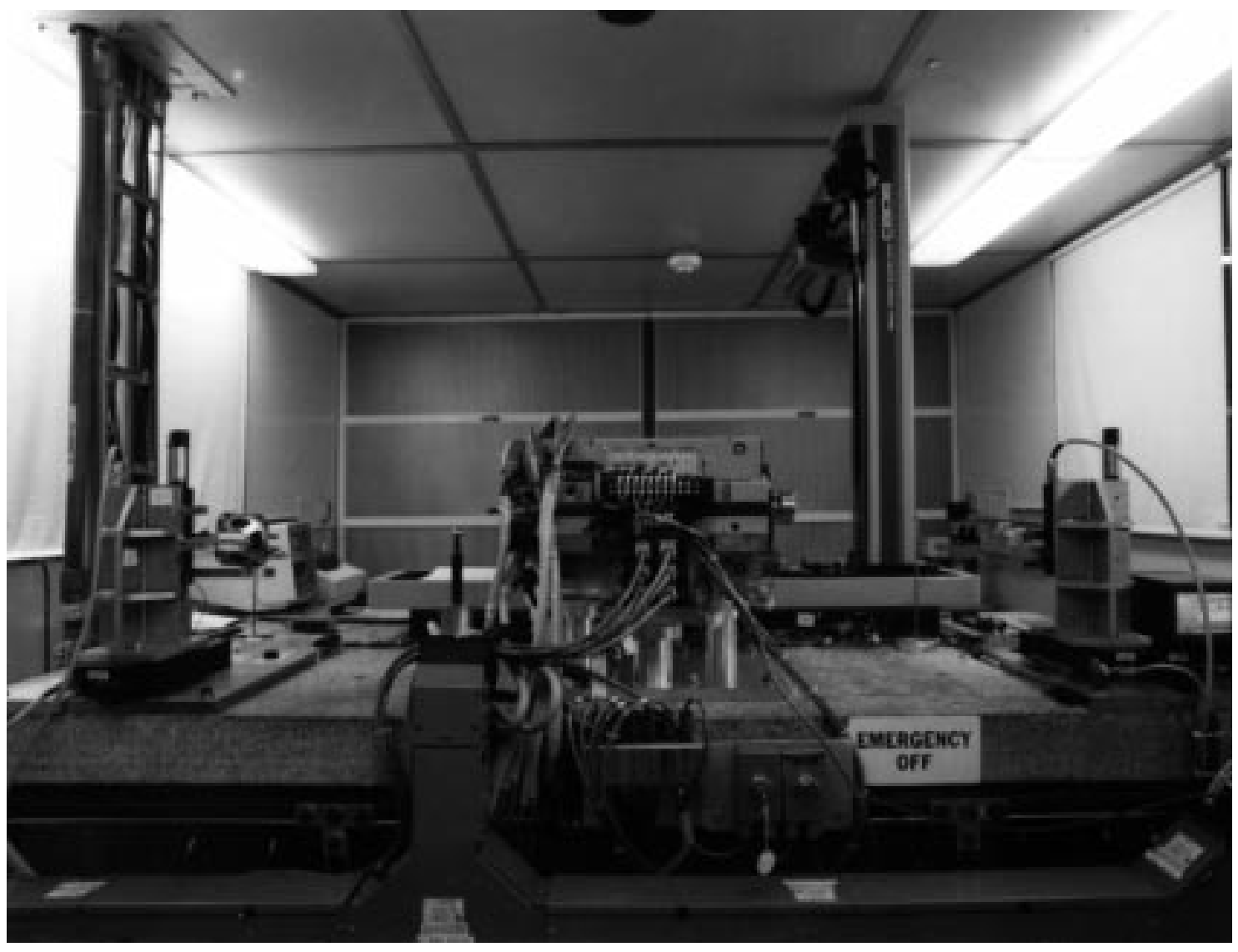

Fig. 30. Fiducialization setup of FFTB magnets at SLAC. 


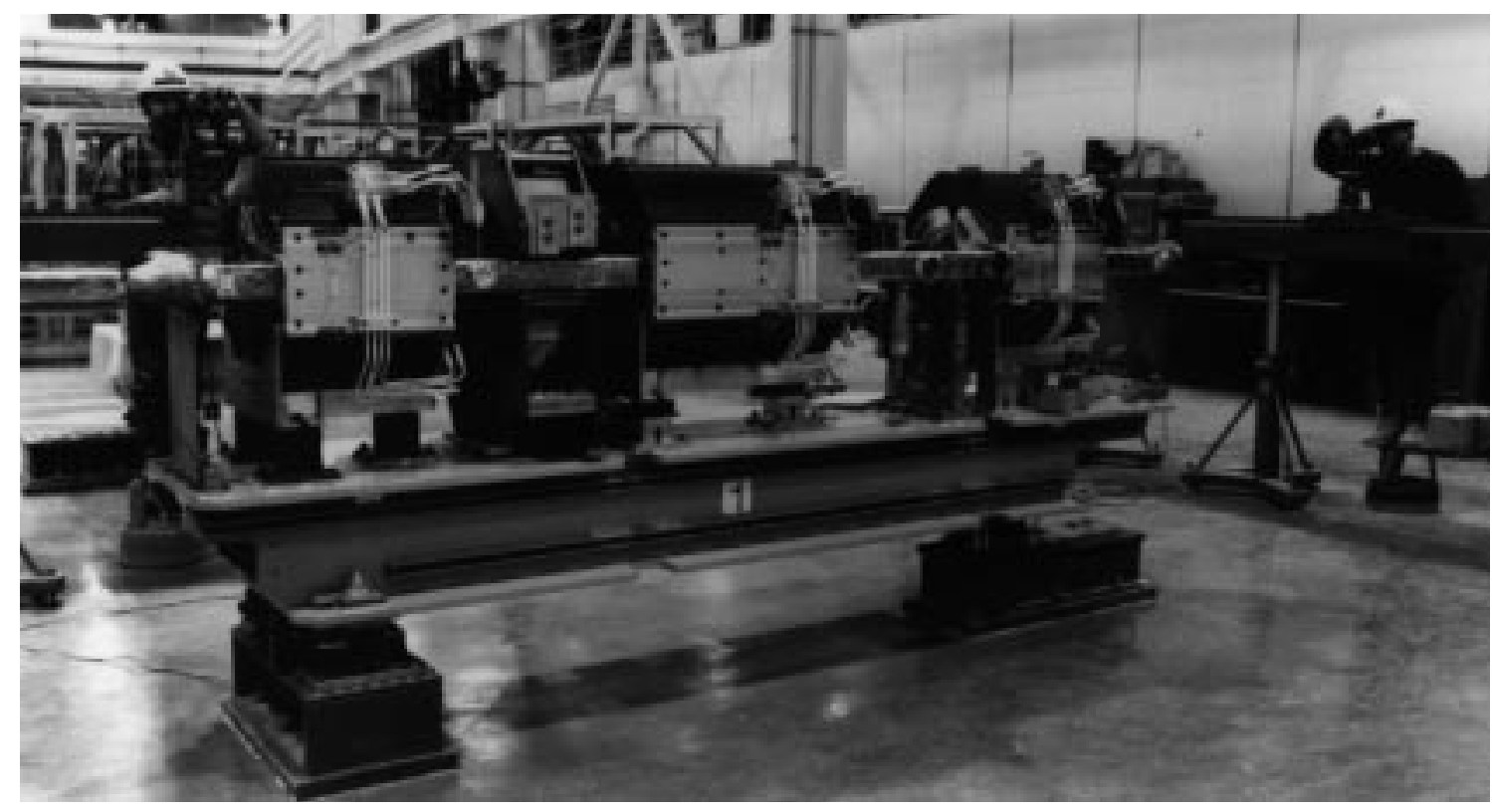

Fig. 31. Prealignment with optical tooling (Argonne APS).

Photo courtesy of Argonne National Lab. 


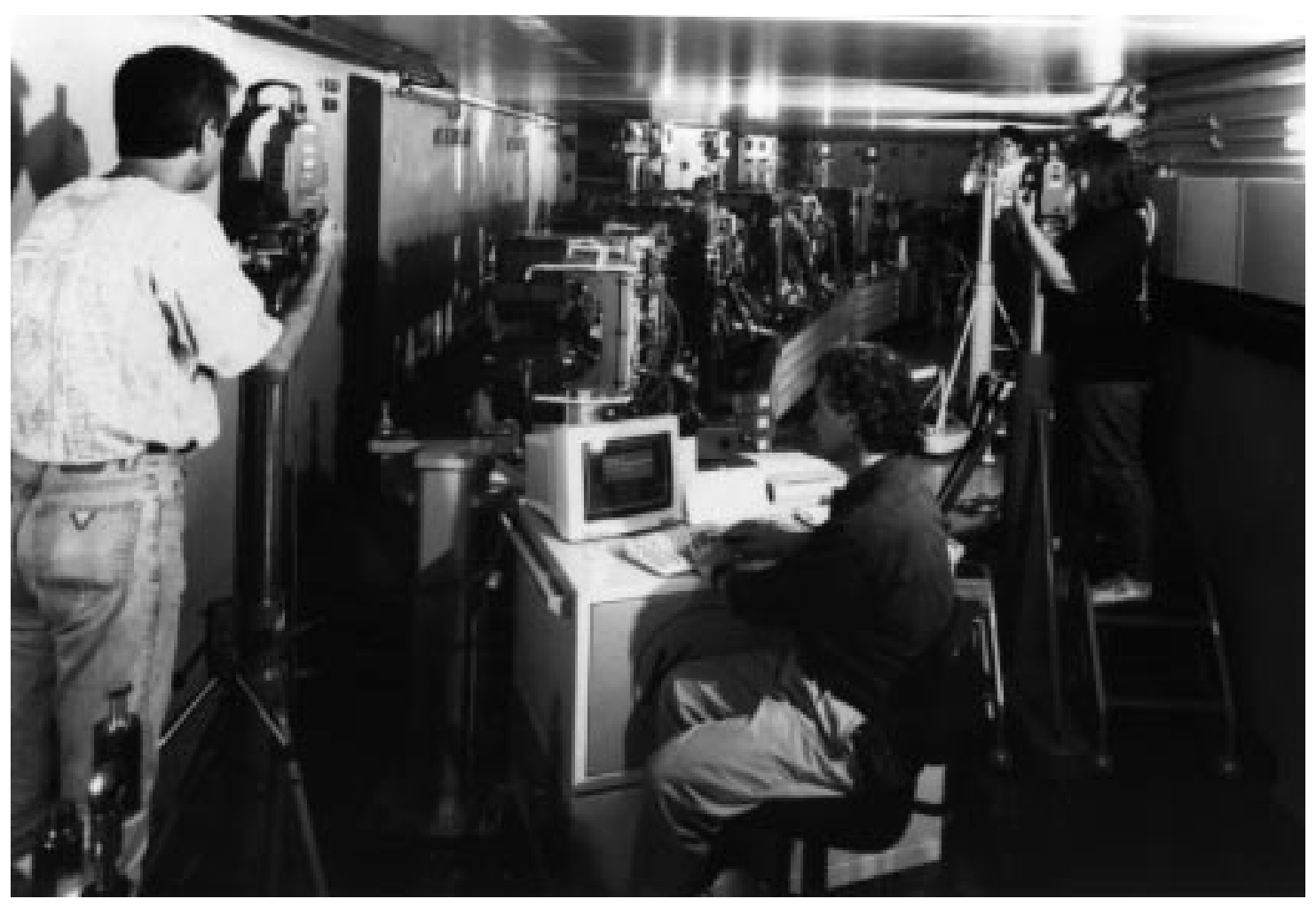

Fig. 32. Prealignment with industrial measurement system.

Photo courtesy of Lawrence Berkeley Laboratory, University of California. 